Published in final edited form as:

Annu Rev Biomed Eng. 2018 June 04; 20: 197-220. doi:10.1146/annurev-bioeng-062117-121156.

\title{
Engineering the Mucus Barrier
}

\author{
T.L. Carlson ${ }^{1}$, J.Y. Lock ${ }^{2}$, and R.L Carrier ${ }^{1,2,{ }^{*}}$ \\ ${ }^{1}$ Department of Chemical Engineering, Northeastern University, Boston, Massachusetts, USA \\ ${ }^{2}$ Department of Bioengineering, Northeastern University, Boston, Massachusetts, USA
}

\begin{abstract}
Mucus selectively controls the transport of molecules, particulate matter, and microorganisms to the underlying epithelial layer. It may be desirable to weaken the mucus barrier to enable effective delivery of drug carriers. Alternatively, the mucus barrier could be strengthened to prevent epithelial interaction with pathogenic microbes or other exogenous materials. The dynamic mucus layer can undergo changes in structure (e.g., pore size) and/or composition (e.g., protein concentrations, mucin glycosylation) in response to stimuli that occur naturally or are purposefully administered, thus altering its barrier function. This review outlines mechanisms by which mucus provides a selective barrier and methods to engineer the mucus layer from the perspective of strengthening or weakening its barrier properties. In addition, strategic design of drug carriers and dosing formulation properties for efficient delivery across the mucus barrier are highlighted and discussed.
\end{abstract}

\section{Keywords}

Mucus Composition; Mucus Barrier; Mucosal Drug Delivery; Mucoadhesive Particles; Mucus Penetration; Mucolytic

\section{Introduction: Mucus as a Natural Barrier}

Mucus lines the wet epithelial surfaces of the respiratory, vaginal, and gastrointestinal tracts, forming a barrier against foreign particulates and pathogens. Mucin, the main structural component present in mucus, is comprised of a protein backbone with intermittent cysteine rich regions which participate in mucin-mucin interactions through disulfide bonds, and a central region containing tandem repeats rich in threonine, serine, and proline(Fig 1). The tandem repeat region is heavily glycosylated with O-linked oligosaccharides, while C- and $\mathrm{N}$-terminal regions primarily consist of $\mathrm{N}$-linked oligosaccharides(1). Each glycan side chain may consist of up to 20 neutral and/or negatively-charged sugars, including sialic acid (N-Acetylneuraminic acid (NeuAc) and N-Glycolylneuraminic acid (Neu5Gc, abundant in non-human mammals)), fucose, N-Acetyl-galactosamine (GalNAc), mannose, galactose (Gal), glucose, and N-Acetylglucosamine (GlcNAc)(2; 3). Mucin sugars may contain carboxyl (e.g., sialic acid) and sulfate (e.g., GalNAc, GlcNAc, Gal(4)) groups that give mucins their overall net negative surface charge. Mucins interact non-covalently (e.g., via

\footnotetext{
*Corresponding Author Contact Information Carrier, R.L, rebecca@ coe.neu.edu.
} 
electrostatic and hydrophobic interactions, hydrogen bonds, physical entanglements) and covalently (e.g., via disulphide bonds) with other mucin molecules and mucus components, which include lipids, proteins, salts, and cellular debris(5), to form a mesh-like viscoelastic gel layer(2).

The mucus layer is crucial in protecting the underlying epithelium from pathogen invasion. For example, Muc2 mucin knockout animals are susceptible to mucosal and systemic infection which results in high mortality rates(6). However, the mucus layer also presents a complex barrier to drug delivery. To penetrate the mucus layer, drug carriers must overcome physical obstructions imposed via the mucus mesh, binding interactions with mucus components, and mucus turnover (i.e. secretion and clearance rates)(7-11).

This review is focused on approaches to engineer the mucus barrier, from the perspective of modifying the properties of and/or designing systems to overcome the barrier. First, natural processes by which mucus physicochemical properties change to maintain a defensive layer and alterations to these properties which occur in different disease states, as well as natural mechanisms by which microbes and viruses overcome the mucus barrier, are discussed. Various methods employed to date that modulate the mucus barrier are then presented, with a focus on exogenous administration of materials. Finally, we review drug carriers and dosing formulation properties that are utilized to overcome the mucus barrier in drug delivery.

\subsection{Natural Mechanisms by Which the Mucus Barrier is Maintained}

Mucus is cleared and renewed multiple times a day to maintain a defensive barrier that can change with respect to viscosity, $\mathrm{pH}$, and composition. Mucus clearance rates and composition vary with anatomical position. Nasal mucus undergoes mucociliary clearance every $10-20$ minutes $(10 ; 11)$, while intestinal mucus is turned over every 50-270 minutes(9). Currently, there are 20 known mucin genes expressed in the body, and each mucin protein has its own distinct core and glycosylation pattern. On MUC5AC, a mucin secreted in the stomach, approximately $50 \%$ of the total O-glycans are neutral or monosulfated. MUC2, the main secreted gel-forming mucin in the intestine, is dominated by negatively-charged sialylated and sulfated glycans in the small intestine, and has a greater amount of fucosylated glycans in the colon than in the small intestine(12).

Mucin sugars (e.g., sialic acid and fucose) can bind viruses and microbes and prevent their penetration of the mucus barrier(13). For example, Streptococcus pyogenes (S. pyogenes) binds sialic acid moieties of submaxillary mucin. When $S$. pyogenes was pretreated with sialic acid $(25 \mathrm{mM})$, adhesion to pharyngeal cell monolayers decreased by $\sim 70 \%$ compared to untreated $S$. pyogenes(14). Moreover, microbial degradation (proteolytic or polysaccharide cleavage) of mucin is influenced by mucin glycosylation patterns (e.g., presence of terminal sialic acid or sulfate groups $)(15 ; 16)$. Colonic mucus is less susceptible than gastric mucus to degradation by Clostridium and Bacteroides species, potentially due to different amounts of sulfated and fucosylated sugars(15).

Mucus composition significantly impacts the rheological properties of mucus(17). For example, changes in the concentration of mucin(18) and non-mucin components (e.g., 
lipid(19), $\operatorname{IgA}(19), \mathrm{DNA}(20))$, and/or $\mathrm{pH}(21)$ can significantly alter mucus viscosity by 5 to $85 \%$. Since mucus is composed of $1-5 \%$ mucin by weight, small increases in mucin concentration are associated with a significant increase in mucus viscosity(22). Over the course of an ovulatory menstrual cycle, fertility is influenced by mucin concentration(22). A two-fold change in mucin amount was detected in human cervical mucus during ovulatory phase, resulting in a thin, watery appearance and a decrease in mucus elastic storage moduli.

Cysteine-rich proteins (e.g., trefoil factor (TFF) and resistin like molecule-beta (RELM- $\beta$ )), are secreted from goblet cells and are associated with an increase in mucus viscosity and mucin (MUC2, MUC5AC) secretion, respectively.(23-25). When RELM- $\beta$ (0.1 nM) was introduced apically to a HT29-CL monolayer, MUC2 secretion was increased $\sim 3.75$-fold over control values. This increase in mucin secretion may explain the method by which rectally administered RELM- $\beta$ ( $50 \mathrm{nM}$ ) minimized inflammatory response and severity in a 2,4,6-Trinitrobenzenesulfonic acid solution (TNBS) induced colitis animal model(25). TFF3 has been shown to form covalent bonds with Muc2 C-terminal domain(26), which may explain increased viscosity of mucin solutions after the introduction of $0.3 \% \mathrm{wt} / \mathrm{vol}$ dimer TFF3 compared to untreated mucin solutions(23). Lysozyme and lactoferrin both interact with mucus electrostatically, and control microbe concentrations by lysing the bacterial cell wall (lysozyme) or sequestering nutrients (lactoferrin)(27-29). The viscosities of collected human sputum and purified bronchial mucin solutions were significantly increased upon addition of lysozyme, which was attributed to strong ionic interactions with negativelycharged mucin sugars $(27 ; 30)$. Immunoglobulins are reported to have transient adhesive interactions via polyvalent low-affinity bonds with mucins, which allow for indirect binding of microbes to mucus, thus impacting their penetration through mucus $(31 ; 32)$. Fluorescence recovery after photobleaching (FRAP) analysis supported transient $\mathrm{IgG}$ and $\operatorname{Ig} \mathrm{A}$ interactions with cervicovaginal mucus (CVM)(31). The addition of IgG to CVM did not alter the diffusion of $200 \mathrm{~nm}$ carboxyl- and PEG- modified polystyrene particles, i.e. representative drug carriers, or mucus structure, but did significantly slow the diffusion of herpes simplex virus (HSV) in CVM, apparently as a result of IgG binding interactions(32). After intravaginal administration of HSV and IgG in mice, HSV infection rates were shown to be inversely proportional to the concentration of $\operatorname{IgG}$, with 25,40 , and $70 \%$ of mice infected at IgG concentrations of $\sim 30,3.3,0 \mu \mathrm{g} / \mathrm{mL}$, respectively.

The $\mathrm{pH}$ of the mucus gel, which has been shown to impact mucus viscoelastic properties, varies throughout the body. For example, gastric and intestinal mucus gels are acidic ( $\mathrm{pH} 2-$ 4) and neutral ( $\mathrm{pH} 7)$, respectively(33). Increasing the $\mathrm{pH}$ of $0.5 \% \mathrm{wt} / \mathrm{vol}$ reconstituted mucin gels from 3 to 7 resulted in a 5-, 9-, and 13- fold increase in diffusivity of $1 \mu \mathrm{m}$ PEG-, amine-, and carboxyl- modified polystyrene particles within the gels(34). The higher viscosity of reconstituted porcine gastric mucin solution at low $\mathrm{pH}(2-4)$, which is representative of gastric mucus, compared to $\mathrm{pH} 6$, was attributed to a reduction in electrostatic interactions. Specifically, it is believed that mucin salt bridges are broken at low $\mathrm{pH}$, resulting in the aggregation of mucin and decreased pore size $(35 ; 36)$. 


\subsection{Alterations to the Mucus Barrier with Disease States}

The importance of the mucus barrier in disease is becoming more apparent, as multiple diseases have been associated with an altered mucus barrier (i.e. increased permeability or viscosity)(37-40). However, the etiologies behind these links are unknown - does mucus dysfunction result in disease, or does disease result in mucus barrier dysfunction? Enhanced understanding of changes to the mucus barrier in disease may motivate novel therapeutic or prophylactic approaches.

\subsubsection{Diseases Associated with Disruption of the Mucosal Barrier-}

Gastrointestinal diseases (e.g., peptic ulcer disease, ulcerative colitis (UC), and necrotizing enterocolitis (NEC)) can be associated with an increase in permeability of the mucus barrier, which may be attributed to decreased mucus thickness and/or goblet cell number. Patients with UC have reduced goblet cell numbers(41), reduced mucus thickness(37; 42), and altered mucin glycosylation pattern(43). Specifically, there is a decrease in sulfate content and a significant change to mucin sugar amounts (i.e. GlcNAc and sialic acid) as compared to healthy individuals(44). The resulting decrease in negative surface charge of mucin fibers may decrease electrostatic repulsions, causing collapse of the mucus gel, thereby reducing mucus thickness. In colonic explants mounted in a custom perfusion chamber, a suspension of 2 and $0.5 \mu \mathrm{m}$ particles penetrated approximately $60 \%(\sim 240 \mu \mathrm{m})$ of the mucus layer in UC explants, whereas particles in healthy explants were unable to penetrate the mucus barrier $(\sim 400 \mu \mathrm{m}$ thick $)(37)$.

Necrotizing enterocolitis (NEC) occurs primarily in premature and low birth weight infants, and is characterized by abdominal bloating, diarrhea, and intestinal infection. NEC patients also have significantly fewer goblet and Paneth cells compared to healthy controls $(45 ; 46)$. Fetal NEC patients had a 83\% decrease in trefoil factor peptide-3 (TFF3) expression, a peptide secreted by goblet cells and upregulated in early stages of mucosal repair, and had no lysozyme-positive Paneth cells compared to healthy patients(47; 48). Since both TFF3 and lysozyme have been shown to interact with mucin, the lack of TFF3 and lysozyme in the premature gut may result in a decreased mucus viscosity and contribute to intestinal necrosis in NEC patients.

Peptic ulcers occur when the gastric mucosa is compromised. The gastric mucosa is lined with a phospholipid surfactant barrier, primarily composed of lecithin, which provides a protective hydrophobic barrier resistant to gastric acids and enzymes(49). Bacterial lipases and pancreatic enzymes can convert lecithin to lysolecithin, reducing hydrophobicity of the protective surfactant barrier(50). Pepsin, a pancreatic enzyme, is a natural protease secreted in the gastrointestinal tract (GIT) that breaks down proteins, including mucin(51). Pepsin 1 (a pepsin associated with peptic ulcers) was shown to have a higher rate of mucolytic activity than pepsin 3 (principle human pepsin) when incubated with purified pig gastric mucin for 30 minutes(52). Thus, increased concentration and activity of pepsin 1 may play a key role in the erosion of the mucus barrier, leading to the formation of ulcers. Moreover, non-steroidal anti-inflammatory drugs (NSAIDs) can destabilize the surfactant layer by binding with zwitterionic phospholipids, thus reducing hydrophobicity and mucosal integrity(53). When NSAIDS, including indomethacin and aspirin, were conjugated to 
dipalmitoyl phosphatidylcholine, a zwitterionic phospholipid, perturbations to the surfactant layer were decreased, reducing gastrointestinal ulceration and bleeding in rats compared to those administered non-conjugated NSAIDs.

1.2.2. Diseases Associated with Increased Mucosal Viscosity-Disease states can also result in a thicker, more viscous mucus layer. Cystic fibrosis $(\mathrm{CF})$, a disease that primarily affects the respiratory tract, is associated with chronic infection, buildup of mucus containing pro-inflammatory cytokines and bacteria, mucus hypersecretion, and increased mucus adhesion to the epithelium(54; 55) (Fig. 2).CF mucus has altered mucin glycosylation (e.g., increased ratio of fucose to sialic acid(56)); increased DNA (0.8 vs. $0.03 \mathrm{~g} / 100 \mathrm{~g}$ wet wt)(57), lipid (16.7 vs. $12.5 \%$ of dry weight)(58), solid (8\% vs. $2.5 \% \mathrm{wt} / \mathrm{wt})$, and salt content (e.g., $\mathrm{Na}^{+}, \mathrm{Ca}^{2+}$, and $\left.\mathrm{Mg}^{2+}\right)(59 ; 60)$; and decreased water content(59). These changes result in increased mucus viscosity and altered microstructure (e.g., pore size: $\mathrm{CF}$ 110-930 nm, control 300-850 nm)(38; 40). Multiple particle tracking (MPT) technique was utilized to demonstrate the altered barrier properties of CF mucus. The transport of $100 \mathrm{~nm}$ polyethylene glycol (PEG)-modified polystyrene particles was slowed further in CF sputum relative to sputum from healthy controls, as reflected in ratios of diffusion coefficients in sputum relative to those in water $\left(\mathrm{D}_{\mathrm{w}} / \mathrm{D}_{\text {eff }}\right)$ of $830(61)$ and 26(62), respectively. Moreover, viscosity was also increased in $\mathrm{CF}$ ( $\sim 30,000$ times the viscosity of water) compared to control $(\sim 13,000$ times the viscosity of water) sputum samples.

Hirschsprung's Disease (HD) is characterized by aganglionic tissue in the distal colon, reduced mucus turnover, and significant increases and decreases in neutral and sulphated mucins, respectively $(63,64)$. In a mouse model of $\mathrm{HD}$, relative to healthy controls, the transport of carboxyl-modified nanoparticles $(200 \mathrm{~nm})$ and Escherichia coli through mucus on excised colonic tissue was significantly hindered(65). Decreased mucin sulfation in HD patients may have diminished electrostatic repulsive forces between mucin fibers and the negatively-charged particles, thus decreasing particle diffusion. HD patients also have increased sialylated mucin secretion in the proximal colon(66), and thus increased microbe binding to sialylated mucins may explain the reduction in microbe velocity in the proximal colon compared to distal colon.

\subsection{Microbial Degradation of Mucus}

Bacterial enzymes, which are secreted, bound to the bacterial outer surface, or present in the periplasm, can degrade mucins through proteolytic or polysaccharide degradation to facilitate microbe penetration and/or colonization of mucus(7). Within the vaginal tract, Gardnerella vaginalis (G. vaginalis), a bacterium associated with bacterial vaginosis (BV), produces sialidase to cleave, sequester, and catabolize sialic acid(67). There was a significant increase in free sialic acid and decrease in bound sialic acid concentration in mouse vaginal content collected 24 hours after inoculation with $G$. vaginalis $\left(\sim 5 \times 10^{7}\right.$ colony forming units (CFUs)) relative to that from control mice. A similar trend was observed in women with BV, who had >3-fold higher free sialic acid levels and significantly less viscous vaginal fluid compared with healthy women(68). Increased sialidase activity may expose the mucin core and sugars to further degradation by proteases and glycosidases 
thus compromising mucus structure and potentially increasing pathogenic microbe colonization(69).

Helicobater pylori (H. pylori) infection is known to cause peptic ulcers, and like pancreatic lipases and NSAIDS, has been shown to compromise the gastric mucus barrier. $H$. pylori colonizes the human stomach by secreting urease to hydrolyze urea, which elevates the $\mathrm{pH}$ of the local environment(70). As the gastric mucus $\mathrm{pH}$ is elevated from 4 to 7 , mucus transitions from gel to solution, reducing bulk viscosity and enabling $H$. pylori to swim through the mucus. The loss of mucus integrity due to $H$. pylori can allow acidic and gastric enzymes present in luminal contents to reach the epithelium, resulting in the formation of peptic ulcers or gastric cancer.

\subsection{Viral Penetration of Mucus}

Viruses utilize similar mechanisms as microbes (i.e. secretion of mucolytic enzymes) to penetrate the mucus barrier and reach the underlying epithelium. Influenza A viruses (IAV) secrete neuraminidase, which selectively cleaves terminal sialic acid residues on mucin fibers(71), minimizing IAV binding and immobilization in, and thus allowing penetration of, the mucus layer. Instead of secreting mucolytic enzymes, some viruses have evolved and altered their surface properties to elude the mucus barrier. FRAP and MPT techniques were utilized to study the diffusion of human papilloma virus (HPV, $55 \mathrm{~nm}$ ), Norwalk virus (NV, $38 \mathrm{~nm}$ ), and herpes simplex virus (HSV, $180 \mathrm{~nm}$ ) through human cervical mucus(72). Two non-enveloped viruses, HPV and NV, were well distributed throughout the mucus gel and diffused at similar speeds in mucus and saline. The high density of positive and negative surface charges resulted in an overall neutral surface charge of capsid proteins on nonenveloped viruses, which is believed to aid in minimizing viral adhesion to mucus. Moreover, non-enveloped viruses have few hydrophobic regions that can interact with hydrophobic domains along mucin fibers. Conversely, HSV, a larger and enveloped virus, appeared to stick to and co-localize with mucus strands, slowing HSV diffusion $\sim 100$ fold in mucus compared to phosphate buffered saline. The viral envelope coats capsid proteins and contains glycoproteins that may interact and bind with mucin glycoproteins, thereby inhibiting virus diffusion through mucus.

\section{Strengthening the Mucus Barrier}

Various exogeneous and endogeneous agents, present in food, detergents, and cholinergic drugs, have been shown to strengthen mucosal barrier properties and/or mucin interactions. These agents can be directly exposed to mucus or systemically administered. In general, the mechanisms behind the action of these agents are often not well understood. These factors could be further explored for their potential use as prophylactic or therapeutic agents to alleviate or prevent disease.

\subsection{Agents that Alter the Mucosal Barrier after Direct Exposure}

Exogenously administered compounds that are also inherently found in mucus and food (e.g., lipids, salts) can significantly strengthen the mucus barrier, as evidenced by decreased particle diffusion through mucus in particle tracking experiments. Amine-, carboxyl-, and 
sulfate- modified polystyrene particles (200 nm) diffused 3-, 30- and 2- fold slower, respectively, when dosed to porcine intestinal mucus with lipids compared to control, and 3-, 4-, and 2- fold lower, respectively, in the presence of $20 \mathrm{mM}$ compared to $5 \mathrm{mM} \mathrm{Ca}^{2+}$, respectively(73). The removal of lipids endogenously present in mucus is associated with significant decreases in mucus viscosity(19), and it is hypothesized that lipids interact with the hydrophobic portions of mucins. Computational models have shown that divalent ions (e.g., $\mathrm{Ca}^{2+}$ ) can be incorporated in transient mucin cross-links limiting gel swelling, which may limit the permeability of the mucus gel(74). Thus, the decrease in particle diffusion within mucus observed after dosing lipids and $\mathrm{Ca}^{2+}$ may result from increased hydrophobic interactions and ionic mucin cross-linking. Monovalent ions (e.g., $\mathrm{Na}^{+}$) can also impact mucin-mucin interactions, apparently due to charge shielding of mucin fibers, which leads to gel de-swelling. A high concentration of sodium chloride $(500 \mathrm{mM})$ compared to a low concentration $(20 \mathrm{mM})$ increased the diffusivity of amine- modified polystyrene particles $\sim 10$-fold in $1 \%$ gastric mucin solution(34). The solubilized salt ions may shield the positively-charged surface of the amine-modified particles or negatively-charged mucin fibers, decreasing electrostatic interactions between diffusing particles and mucus and consequently increasing particle diffusion.

Other dietary compounds have also been shown to alter mucus barrier properties. Particle tracking microrheology and atomic force microscopy revealed green tea polyphenol epigallocatechin gallate (EGCG) increased viscosity and aggregation of purified MUC5B and MUC7 salivary mucin solutions(75). TFF, which is endogenously present in mucus as noted previously, is also present in breastmilk. TFF3 has been shown to protect against intestinal colitis in a dextran sodium sulfate (DSS)-induced mouse model, which had increased LPS concentration, and decreased mucus thickness and elasticity compared to healthy controls. When orally dosed, TFF3 dimer reduced DSS-induced colitis(76), potentially by binding with mucin and increasing mucus viscosity(24). Interestingly, other components in breast milk (i.e. lysozyme, mucin, immunoglobulins, TFF, and lipids) are also endogenously present within mucus, and significant to its barrier properties, as noted previously. When premature infants with NEC, a disease state prone to infection and characterized by an altered mucus composition, were given an exclusively human milk diet, NEC incidence was reduced from 3.4 to $1 \%$, potentially due to the components in milk(77).

Orally introduced gelatins can also strengthen the mucus barrier. When DSS-induced mice were treated with gelatin tannate, the mucus layer thickness and elasticity as measured by atomic force microscopy were similar to healthy controls, and disease severity was decreased. It was hypothesized that gelatin tannate forms a protective film over the mucus layer, thus preventing mucus breakdown, and modulates the gut microbiota composition (e.g., decrease in potentially pathogenic strains of Enterobacteriaceae and Enterococci)(78).

Detergents have also been shown to alter mucus barrier and structural properties. A nonionic detergent, nonoxynol-9 (N9), frequently used as a spermicide and microbicide, did not alter bulk viscous and elastic moduli of CVM, but did impact transport properties and mucus pore size. A $10 \%$ N9 solution added to mucus at $1 \%$ volume decreased the diffusion of 200and 500- nm PEG- modified particles by 160- and 140- fold, respectively, compared to control(79); however, the diffusion of 100- nm PEG- modified particles was not altered. N9- 
treated and control mucus samples had $<15 \%$ and $>80 \%$ of pores larger than $200 \mathrm{~nm}$, respectively. It was hypothesized that $\mathrm{N} 9$ disrupts hydrophobic interactions between fibers resulting in a mucus mesh with smaller pore size.

2.1.1. Stimulation of Mucin Secretion-Mucin secretion from goblet cells occurs through two distinct pathways: continuous unregulated or regulated mucin secretion, which is the rapid release of apically stored mucin granules in response to microbial toxins or exogenous agents(80). Mucin secretion can be regulated by type- 2 chloride channel (ClC-2) activators (e.g., lubiprostone) or parasympathetic and cholinergic $\mathrm{Ca}^{2+}$ dependent agents (e.g., acetylcholine, carbachol). These agents can be used to treat intestinal motility disorders (e.g., chronic and IBS-associated constipation), and have been shown to induce mucin release and chloride secretion when administered to the lumen (via oral dosing) or serosa (via intraperitoneal administration or addition to basolateral compartment of an organ culture dish) $(81 ; 82)$. Acetylcholine induced a higher level of mucin secretion when applied to the serosa compared to luminal application(83), depleting goblet cells of mucin within 60 mins compared to untreated controls(82). Acetylcholine may stimulate innervated mucus cells or increase hydrostatic pressure to induce mucin release $(84)$. When chloride $\left(\mathrm{Cl}^{-}\right)$ secretion was inhibited after acetylcholine treatment, liquid secretion was blocked up to $70 \%$, and there was an accumulation of mucin in excised porcine bronchial gland ducts(85). Intraperitoneal injection of carbachol stimulated rat gastrointestinal mucin secretion $~ 1.7-$ fold overall, with the effect dependent on anatomical position. Secretion was unchanged in the cecum and proximal colon, while the distal colon and jejunum had 2- and 5- fold increase in mucin secretion compared to control(86). Carbachol elevates cytosol levels of $\mathrm{Ca}^{2+}$, which stimulates mucin secretion(87). The effect of calcium $\left(\mathrm{Ca}^{2+}\right)$ concentrations on mucus secretion was investigated with excised avian trachea tissue mounted in a glass organ bath. When $\mathrm{Ca}^{2+}$ concentrations are low luminally or high submucosally, mucin secretion rates were increased. Interestingly, addition of both acetylcholine and $\mathrm{Ca}^{2+}$ has an additive effect on mucin secretion when applied to both the lumen and submucosa(83). Oral dosage of lubiprostone stimulated $\mathrm{Cl}^{-}$secretion and increased gastric mucin secretion $85 \%$ compared to untreated control (54.5 vs. $98.4 \mathrm{mg} /$ hour), which increased gastrointestinal lubrication and transit times(88).

Dietary fiber constituents (e.g., glucuronic acid, galacturonic acid), food additives (e.g., sodium alginate), and bacterial metabolites (e.g., acetate and butyrate), administered into a rat colonic loop increased mucin secretion in a dose dependent manner(89). Bacterial fermentation of glucuronic acid, and galacturonic acid produces short chain fatty acids (SCFA) (e.g., acetate, butyrate) which act as an energy source for epithelial cells and induce mucin secretion through activation of cholinergic nerves(90). Dietary long chain fatty acids (LCFAs) (e.g., palmitic acid, stearic acid, oleic acid, linoleic acid, docosapentaenoic acid) increased MUC2 production when added to HT29-MTX mucus secreting cell lines(91). Palmitic acid may increase goblet cell differentiation and maturation by increasing hepatocyte nuclear factor 4 alpha expression, a critical component in goblet cell maturation. Moreover, palmitic acid may covalently attach to mucin amino acids (e.g., serine and threonine) regulating MUC2 production and secretion. Phytonutrients in plant extracts altered the expression of Reg3 $\gamma$ (an antimicrobial peptide), TFF3, Muc2, and Muc3 when 
administered in the drinking water of mice for 7 days. Eugenol, a phytonutrient found in clove oil, significantly increased inner mucus layer thickness from 20 to $33 \mu \mathrm{m}$, decreased TFF3 expression, and increased Reg3 $\gamma$ expression(92). Antibiotics minimized the effect of eugenol, thus it was hypothesized that the action of eugenol is influenced by the intestinal microbiota. Eugenol may increase microbe-mediated utilization of mucin and production of bacterial metabolites (i.e. SCFA), which have been shown to increase mucus productiont $(90)$.

Some agents have been shown to increase goblet cell number. Six-week old mice fed high fat diets (45 wt\% of lipid) had increased goblet cell number in all intestinal segments as compared to mice fed low and moderate fat (2.6 and $22 \mathrm{wt} \%$ of lipid) diets(93). High fat diet treated animals had increased plasma concentrations of adiponectin(94) and leptin(95) which have been previously shown to increase goblet cell number and Muc2 production. Notch $\gamma$-secretase inhibitors (e.g., $N$-[(3,5-Difluorophenyl)acetyl]-L-alanyl-2phenyl]glycine-1,1-dimethylethyl ester (DAPT)) added to HT29 cells co-cultured with epithelial colorectal cells (Caco-2) increased mucin production by $10-15 \%$ compared to untreated controls(96). In another study, cranberry bean pretreatment increased mucin content and decreased damage in DSS-induced mice compared to untreated DSS-induced mice. When healthy control mice were treated with cranberry beans, mice had increased number of goblet cells per crypt, mucus content per colon crypt, and Muc1 mRNA levels compared to untreated controls, which may have aided in protecting against colitis(97).

\subsection{Beneficial Role of Probiotics on the Mucus Barrier}

Probiotics are non-pathogenic microorganisms proposed to play a beneficial role in health, for example by promoting the survival of commensal bacteria and/or protecting the gut from pathogenic microbes(98). Probiotics have been shown to have anti-inflammatory(99) properties and decrease disease severity in rat pups with necrotizing enterocolitis or stressinduced hyperpermeability $(100 ; 101)$; however, the mechanisms are generally not well understood. Probiotics have been reported to impact mucin expression, goblet cell number, and mucin glycosylation, supporting the concept that the benefits of probiotics are due in part to their impact on the mucus barrier.

Oral dosing of $L$. farciminis prevented changes in intestinal permeability and minimized changes to mucin glycosylation resulting from water avoidance stress(100). Intestinal permeability represents a composite measurement of mucus permeability as well as that of underlying cell layers, and thus it is not possible to isolate the changes to the mucus barrier. Incorporation of probiotics, specifically L. rhamnosus and L. plantarum 299v, significantly increased HT29 MUC3 expression compared to control(102).Similarly, in another study, mice given Ultrabiotique® (Lactobacillus acidophilus, Bifidobacterium lactis, Lactobacillus plantarum and Bifidobacterium breve) for 7 days had an increased number of goblet cells per crypt and increased production of mucus compared to controls(103).

Probiotic adhesion to mucus is strain specific and occurs through electrostatic (ionic bridging) and hydrophobic interactions. Probiotics also use lipoteichoic acids on the cell wall of gram-positive microbes or external appendages to adhere and persist in mucus(98). When three Lactobacillus probiotic strains were added to MUC3 mucus-producing HT29 
cells, each strain showed different levels of adhesion: $11 \%$ of Lactobacillus rhamnosus, $1.6 \%$ of Lactobacillus plantarum 299v), and $0.13 \%$ of Lactobacillus acidophilus DDS-1 adhered to HT29 monolayers after four hours of incubation. Likely due to competitive binding and steric hindrance, L. rhamnosus, L. plantarum 299v, and L. acidophilus decreased the amount of enteropathogenic E. coli (EPEC) adhesion by 57, 72 and $22 \%$, respectively(102).

Probiotics can also alter the intestinal lumen/mucosal barrier environment by secreting lactic acid, peroxides, and antimicrobial substances (e.g., toxins) impacting microbiome composition. A laboratory culture of 10 Lactobacillus and 5 Bifidobacterium strains inhibited pathogen growth of 3 Salmonella and 3 Listeria strains by secreting lactic acid, which decreased $\mathrm{pH}$ levels, and secreting bacteriocin, a peptidic toxin that inhibits bacteria growth(104). Spent media from a Lactobacilli crispatus culture containing $\mathrm{H}_{2} \mathrm{O}_{2}$ inhibited the growth of Staphylococcus aureus which was attributed to the oxidative effect of $\mathrm{H}_{2} \mathrm{O}_{2}$ or its metabolites $\left(\mathrm{OH}^{-} ; \mathrm{O}^{2-}\right)(105)$.

\section{Weakening the Mucus Barrier}

It is also sometimes desirable to break down the mucus barrier to allow for more efficient drug delivery or to remove mucus buildup. Enzymes and other chemicals can be used to alter mucus structure and decrease viscosity (Fig 3). Moreover, commonly ingested food components may alter the structural integrity of the mucus barrier.

\subsection{Enzymatic Breakdown of Mucus}

As mucus is a complex network of crosslinked proteins, proteolytic enzymes can be utilized to disrupt peptide bonds and cleave non-glycosylated mucin domains in order to degrade mucin protein backbone and/or proteins in the mucus gel and enhance permeability of the mucus gel. These enzymes also play a major role in the natural turnover of the mucus layer. For example, proteolytic enzymes (trypsin, papain, and bromelain are naturally found in the digestive tract, papaya, and pineapple, respectively added to native pig intestinal mucus for 12 hours at $37^{\circ} \mathrm{C}$ had variable efficiency in cleaving the mucus network, which was also dependent on $\mathrm{pH}(5.0,6.5$, and 8.0)(106). Bulk rheological analysis showed that papain significantly reduced mucus viscosity after 1 hour regardless of $\mathrm{pH}$. Both trypsin and bromelain were most active at their optimal $\mathrm{pH}$ of 5 and 8 , respectively, but overall mucolytic effect for each enzyme was lower than that of papain.

Deoxyribonuclease (DNase) has been explored to enzymatically degrade DNA in mucus and thus decrease mucus viscosity. The higher DNA concentration in CF mucus, as mentioned previously, results in increased mucus viscosity, which contributes to decreased mucus clearance and increased risk of infection. A small amount of recombinant human DNase I ( 8 $\mu \mathrm{g} / \mathrm{mL}$ ) decreased the viscosity ( $732 \mathrm{cP}$ to $188 \mathrm{cP}$ ) and overall DNA molecular weight in CF sputum after 15 minutes(107). In another study, diffusion of $500 \mathrm{~nm}$ carboxyl-modified polystyrene particles was enhanced after piglet intestinal mucus was exposed to DNase(20). 


\subsection{Other Chemical Methods to Alter Mucus Structure}

In addition to enzymatic degradation, other chemical methods have been used to alter mucus structure to allow for both better drug delivery and treatment of diseases associated with mucus overproduction. Mucolytics, expectorants, and mucokinetic agents have been used to help clear viscous mucus from the respiratory tract of patients with chronic airway obstructions by depolymerizing mucin $(108 ; 109)$, increasing airway water volume to promote sputum secretion(109; 110), and removing adhesive mucus secretions from the epithelium $(111 ; 112)$, respectively. $\mathrm{N}$-acetylcysteine (NAC), a mucolytic, reduces mucin cross-linking by cleaving disulfide bonds(108), which constitute important intermolecular and intramolecular mucin cross-links. NAC decreased mucus viscosity, increased pore size, and increased the diffusion rate of $200 \mathrm{~nm}$ PEG- modified particles within CF mucus 10-fold compared to untreated CF mucus. Another cysteine-containing compound, Scarboxymethlycysteine (carbocisteine), affects sialyltransferase activity in goblet cells resulting in increased sialylated mucin and decreased fucosylated mucin levels(113). When patients with chronic bronchitis were treated with carbocisteine ( $2.7 \mathrm{~g}$ for 4 days), there was a significant reduction in viscosity and increase in mucociliary transport, which may be related to the altered mucin glycosylation(114).

Expectorants, such as guaifenesin (e.g., Mucinex or Robitussin), are used to draw water into the bronchi lumen to increase the sputum volume, thus improving the effectiveness of a cough(109). In an air-liquid interface culture of primary human airway epithelial cells, guaifenesin reduced MUC5AC transcription and secretion from storage granules(110). There was also an increase in mucociliary transport rates (66\% higher than control) and reduction in mucus elasticity and viscosity as measured by bulk rheology.

Mucokinetic agents can increase mucociliary clearance by stimulating cilia beat frequency or reducing mucus adhesion to the epithelium(109; 111). In the airways, a thin layer of surfactant separates mucus from the cilia, and the addition of phospholipids can disrupt this surfactant layer, thus reducing mucus adhesivity to the epithelium(112). To study this phenomenon, respiratory mucus was deposited on a glass slide coated with fatty acids, and mucus adhesion and cough was analyzed in a custom testing apparatus.

Phosphatidylglycerol distearoyl significantly improved cough clearance, which was attributed to the disruption of the surfactant layer and decrease in mucus adhesion(115). Another phospholipid, phosphatidylglycerol dipalmitoyl, also decreased adhesion but was unable to significantly improve clearance.

Other chemical agents have also been shown to disrupt ionic interactions to directly alter mucin cross-links. For example, chelation of calcium ions $\left(\mathrm{Ca}^{2+}\right)$ from mucus results in the rapid swelling, hydration, and dispersion of purified gastric mucin networks $(116 ; 117)$. Calcium chelators bicarbonate $\left(\mathrm{HCO}_{3}{ }^{-}\right)$and ethylene glycol-bis( $\beta$-aminoethyl ether)$\mathrm{N}, \mathrm{N}, \mathrm{N}^{\prime}, \mathrm{N}^{\prime}$-tetraacetic acid (EGTA) impacted viscosity of mucin aggregates and dispersion of mucin fibers(118). Specifically, $8.2 \mathrm{mM} \mathrm{Ca}^{2+}$ was added to $1 \mathrm{ng} / \mathrm{mL}$ porcine gastric mucus diluted in buffer to obtain mucin aggregates $\sim 9 \mu \mathrm{m}$ in diameter. The addition of $20 \mathrm{mM}$ $\mathrm{HCO}_{3}{ }^{-}$or $5 \mathrm{mM}$ EGTA sequestered bound $\mathrm{Ca}^{2+}$ from mucin aggregates, which dispersed mucin fibers, decreasing the diameter of mucin aggregates to $\sim 4.5 \mu \mathrm{m}$. Human alveolar basal epithelial cells (A549) were cultured with $1 \mu \mathrm{M}$ ionomycin to stimulate secretion of mucin 
granules, and the swelling rate of secreted mucin, which reflects mucin fiber dispersion and viscosity of mucus gel, was analyzed via phase-contrast video microscopy. Mucin gelswelling rate, quantified by video microscopy, increased $160 \%$ and $360 \%$ in the presence of $10 \mathrm{mM} \mathrm{HCO}_{3}{ }^{-}$and $10 \mathrm{mM} \mathrm{EGTA}$, respectively, relative to control, thus indicating a decrease in viscosity.

Urea and guanidinium hydrochloride have been reported to disrupt intermolecular and intramolecular mucin hydrogen bonds(119). When $25 \mathrm{mg} / \mathrm{mL}$ porcine gastrointestinal mucin (PGM) was treated with $2 \mathrm{M}$ urea, there was a decrease in gel viscosity and increase in 500 $\mathrm{nm}$ carboxyl- modified particle diffusion compared to untreated PGM. Similarly, 8M guanidinium hydrochloride addition to $20 \mathrm{mg} / \mathrm{mL}$ PGM solution resulted in a viscous liquid with decreased viscosity compared to untreated PGM. Thus the disruption of mucin bonds, especially ionic, disulfide, and hydrogen bonds, can strongly impact the structural integrity of the mucus gel.

\subsection{Luminal Food Components Can Decrease Mucus Thickness}

Food components and digested by-products can also alter the integrity of the mucus barrier and affect drug delivery. Chronic long-term oral exposure to two emulsifiers, carboxymethylcellulose and polysorbate-80, which are present in some processed foods and incorporated as drug excipients, has been shown to result in decreased intestinal mucus thickness(120). These emulsifiers, added to drinking water of mice for 12 weeks, also resulted in inflammation and metabolic syndrome, as well as increased microbe proximity to the epithelium (Fig 4). Although mucus thickness was altered, it is unclear if this was a direct result of emulsifier exposure to the mucus layer, or due to changes in mucus production after chronic long-term exposure of epithelium.

Acute alcohol exposure has been shown to reduce mucosal hydrophobicity by extracting free fatty acid (FFA) and lipids from the mucus layer(121). Rat intestinal loops injected intraluminally with 0-40\% alcohol had acute, concentration-dependent mucosal changes, i.e. increase in permeability correlated with decreases in mucosal hydrophobicity, i.e. contact angle. At high alcohol concentration (40\%), DNA, protein, mucus, and FFA concentrations in the lumen were significantly increased.

\section{Considerations for Developing Drug Carriers to Enhance Permeation through Mucus}

As noted previously, the mucus barrier can be modified by endogenous or exogenous agents (e.g., luminal stimuli from ingested materials), and mucus barrier modifications may have direct implications for effectiveness of drug delivery targeted at mucosal sites. However, to minimize potential detrimental effects associated with weakening mucus structural integrity, such as exposure of underlying tissues to microbes, drug delivery carriers themselves can be modified to penetrate mucus without compromising the entire mucus layer. Drug carriers can be optimized to penetrate mucosal barriers by altering particle size and surface chemistry, in addition to carrier solution properties (Fig 5). 


\subsection{Impact of Particle Size}

Drug carrier size plays an important role in influencing particle penetration and diffusion through mucus due to steric obstruction from the mucus mesh structure with pore size ranging from 10-1800 $\mathrm{nm}$. For example, an average pore size of $340 \pm 70 \mathrm{~nm}$ was reported in human cervicovaginal mucus(122), while a pore size of $150 \pm 50 \mathrm{~nm}$ was measured in human nasal mucus collected from patients with chronic rhinosinusitis(123). Drug carriers larger than the mucus pore size may be size-excluded and unable to diffuse through the mucus gel. For example, there was a decrease in the diffusion rate of particles through porcine intestinal mucus with increasing particle size from 20 to $500 \mathrm{~nm}$ (124). Effective diffusivities of 20,100 , and $500 \mathrm{~nm}$ carboxyl-modified particles were $0.13,0.06$, and 0.021 $\mu \mathrm{m}^{2} / \mathrm{s}$, respectively.

Self-nanoemulsifying drug delivery systems (SNEDDS), which are composed of water, oil, and surfactants, have been developed as drug carriers for poorly water soluble drugs. SNEDDS are able to diffuse through the mucus gel because of their small size, shape deformation, and minimal interaction with mucus components(125). Surfactant type (e.g., Cremophor RH 40 and triacetin) and concentration impacted permeation through mucus. Formulation with Cremophor resulted in smaller particles $(<50 \mathrm{~nm})$ that were able to diffuse faster through porcine intestinal mucus than particles formulated with triacetin $(30-400 \mathrm{~nm})$.

\subsection{Particle Surface Functionalization}

Since mucus is composed of charged entities (e.g., negatively-charged mucin fibers), surface functionalization can impact the interaction (e.g., electrostatic) between a drug carrier and mucus, thus altering drug carrier diffusion rate and penetration depth. Two approaches have been investigated for enhancing drug delivery at mucosal sites: mucoadhesive particles which can increase particle retention within the gastrointestinal tract, and mucus penetrating particles which can diffuse relatively quickly through a mucus gel by minimizing interactions with mucus.

4.2.1. Mucoadhesive Drug Carriers-Mucoadhesion is the adhesion of a material to the mucosal membrane by polymer interpenetration or entanglement, and/or formation of chemical bonds or electrostatic interactions, with the mucin network $(126 ; 127)$. Both natural (e.g., cellulose, chitosan, guar, xanthan, pectin, and alginate) and synthetic (e.g., polyacrylic acid (PAA) derivatives, poly(vinyl alcohol), and poly(N-vinyl pyrrolidone)) polymers have been incorporated in mucoadhesive drug carriers(127). Polymer concentration, hydrophilicity, molecular weight, cross-linking, and swelling can all impact mucoadhesion(128).

One synthetic mucoadhesive polymer, polyacrylic acid (PAA, Carbopol®), contains a high proportion of carboxylic acid groups that can undergo hydrogen bonding with mucus. The viscosity of a Carbopol ${ }^{\circledR}$ and purified porcine stomach mucin mixture was dependent on $\mathrm{pH}$, in addition to polymer and solution salt concentrations(129). The specific viscosities of solutions containing $2 \mathrm{mg} / \mathrm{mL}$ mucin and $4 \mathrm{mg} / \mathrm{mL}$ Carbopol ${ }^{\circledR}$ at $\mathrm{pH} 2$ and 7 were 1.0 and 7.4 , respectively. The increase in viscosity at $\mathrm{pH} 7$ was attributed to the deprotonation of 
carboxyl groups resulting in electrostatic repulsion of expanded and rigid Carbopol ${ }^{\circledR}$ polymer chains.

Mucoadhesive properties of particulate drug carriers can be enhanced by incorporating more than one polymer. Polyglycerol ester of fatty acid (PGEF)-Carbopol ${ }^{\circledR}$ 934P microspheres showed higher in vitro adhesion to rat stomach and intestinal mucus compared to PGEF microspheres(130). After oral administration, the PGEF-Carbopol@ were also retained longer within the gastrointestinal tract than PGEF microspheres. It was hypothesized that hydrated and swelled Carbopol ${ }^{\circledR}$ polymer anchored the PGEF microspheres to the mucus layer. Other polymer mixtures, including polyacrylic acid (Carbopol® 934P) and Eudragit ${ }^{\circledR}$ RL 100 (copolymer of acrylic and methacrylic acid), have been utilized as a coating for poly(2-hydroxyethyl methacrylate) microspheres(131). As a single component coating, Eudragit did not have any mucoadhesive properties (detachment force $=0 \mathrm{mN} / \mathrm{cm}^{2}$ ), while Carbopol ${ }^{\circledR}$ 934P had a detachment force of $6.06 \pm 0.24 \mathrm{mN} / \mathrm{cm}^{2}$ from porcine duodenum mucosa. When Eudragit ${ }^{\circledR}$ RL 100 was combined with Carbopol ${ }^{\circledR}$ (9:1), the mixture had a detachment force of $5.95 \pm 0.29 \mathrm{mN} / \mathrm{cm}^{2}$, which was similar to Carbopol@ alone. However in rat perfusion studies, the mixture of Eudragit ${ }^{\circledR}$ RL 100 and Carbopol ${ }^{\circledR}$ was retained longer in the intestine compared to Carbopol ${ }^{\circledR}$ alone. The incorporation of Eudragit ${ }^{\circledR}$ RL 100 may limit the hydration and swelling of Carbopol@, thus providing a longer mucoadhesive contact.

Thiol groups can be conjugated to drug carriers or polymers to form disulfide bonds with cysteine-rich regions of mucus glycoproteins. Cationic chitosan was modified with thiol groups ( $203 \pm 71 \mu \mathrm{mol}$ thiol groups per gram polymer), and the rotating cylinder method was used to investigate mucoadhesion of chitosan-thiol conjugates or unmodified chitosan at $\mathrm{pH} 3$, 5, and 7(132). Mucoadhesive properties of chitosan-thiol conjugates were dependent on $\mathrm{pH}$; specifically, lower $\mathrm{pH}$ resulted in higher mucoadhesion which may be attributed to higher proton concentration on thiol conjugates and thus reactivity to form disulfide bonds. After orally dosing chitosan-thiol conjugate particles loaded with calcitonin to rats, there was a significant increase in calcitonin absorption in serum compared to unmodified chitosan particles(133).

4.2.2. Mucus Penetrating Drug Carriers-While mucoadhesion may increase drug carrier retention in mucus, mucoadhesive particles are vulnerable to clearance as mucus is secreted and cleared. Thus, it is important to consider not only the length of time a drug carrier can reside in the mucus layer, but also if a drug carrier is able to reach the epithelium before it is cleared. Mucus penetrating particles (MPP) diffuse through the mucus layer by minimally interacting with other particles or mucin fibers, resulting in increased particle penetration and distribution(62; 134-136). Some MPP surfaces, e.g., particles with PEG coatings, are neutrally charged, similar to surface coatings of viruses, which facilitates penetration of the mucus barrier by avoiding interactions with the electrostatically charged mucins.

Various polymers (e.g., PEG, Pluronic $®$, or Polyvinyl Acetate (PVA)) have been used to coat carboxyl- modified polystyrene (PS) and poly(lactic-co-glycolic acid) (PLGA) particles to form near neutral MPP approximately $200 \pm 75 \mathrm{~nm}$ in diameter(62; 134-136). The 
average diffusion coefficients in mucus $\left(\mathrm{D}_{\mathrm{m}}\right)$ compared to theoretical diffusion in water $\left(\mathrm{D}_{\mathrm{w}}\right)$ for these coated particles (PS/PVA $\left(\mathrm{D}_{\mathrm{m}} / \mathrm{D}_{\mathrm{w}}=4000\right)$, PS/PEG $\left(\mathrm{D}_{\mathrm{m}} / \mathrm{D}_{\mathrm{w}}=6.3\right)$ and PLGA/ Pluronic $\left.{ }^{\circledR} \mathrm{F} 127\left(\mathrm{D}_{\mathrm{m}} / \mathrm{D}_{\mathrm{w}}=20\right)\right)$ were degrees of magnitudes lower than for uncoated (PS $\left(D_{m} / D_{w}=9000\right)$ and PLGA $\left.\left(D_{m} / D_{w}=1000\right)\right)$ particles, indicating surface coatings resulted in a more diffusive particle $(8 ; 137)$. PLGA/Pluronic ${ }^{\circledR}$ F127 particles diffused 280 -fold faster in human cervicovaginal mucus and PLGA/PEG particles diffused 800-fold faster in human CF sputum compared to uncoated PLGA $(8 ; 137 ; 138)$. Intranasal administration of particle solutions $(60,100$, or $300 \mathrm{~nm})$ revealed that uncoated particles (PS, PLGA) were clumped, non-evenly distributed, and vulnerable to clearance while MPP PEG-coated particles were evenly distributed along the mucosa. The ability of MPP to penetrate and diffuse through mucus is influenced by both the type of coating material and coating coverage. PS particles coated with increasing amounts of PEG (1-8\%) showed concentration dependent increases in particle diffusion, however PEG coating $>10 \%$ did not further increase particle diffusion and distribution to a significant degree(139). These polymer coatings can also be used with other biocompatible carriers. PEG-coating of DNA-poly( $\beta$-amino ester) (PBAE) nanoparticles increased coverage by $\sim 50 \%$ and $\sim 20 \%$ in the large airways and lung parenchyma, respectively(140). Similarly, PEG- coated liposomes had increased retention and distribution following Intravaginal administration(141).

Zwitterionic materials, which contain positively and negatively charged moieties resulting in an overall net neutral charge, have been used as particle coatings as well, due to their ability to resist protein binding, as well as bind water molecules more strongly and stably due to electrostatically induced hydration, as compared to PEG molecules(142).

Dilauroylphosphatidylcholine (DLPC) is a zwitterionic polybetaine that contains a hydrophilic phosphatidylcholine headgroup and hydrophobic dodecylic acid chains. DLPC self-assembles on polylactic acid (PLA) particles ( $\sim 90 \mathrm{~nm}$ in diameter) resulting in a neutral and hydrophilic coating(143). Poly(vinyl alcohol) PVA-coated PLA nanoparticles ( 120 nm) resulted in 20-fold higher aggregation of mucin fibers (measured by fluorescence intensity of precipitated fluorescent particle-mucin aggregates) upon incubation with purified porcine mucin ( $2 \% \mathrm{wt} / \mathrm{vol})$ relative to DLPC-coated PLA particles. Moreover, DLPC-coated PLA particles had 6.3-fold higher apparent permeability through human cervicovaginal mucus as compared to PVA-coated PLA particles. DLPC-coated PLA particles also had $~ 4.5$ fold increase in Caco-2 cellular uptake compared to PEG-coated PLA particles. Thus, zwitterionic coatings, which can be designed to be biocompatible, bioinert, and hydrophilic.

Another approach to improve nanoparticle penetration through mucus is to incorporate proteolytic enzymes. For example, papain was complexed with poly(acrylic) acid (PAA), a polyelectrolyte, to produce nanoparticles $\sim 190 \mathrm{~nm}$ in diameter(106). Papain-PAA nanoparticles had a significantly faster transport rate ( 2.5 fold increase) through porcine intestinal mucus sandwiched between polycarbonate filters in a Transwell-Snapwell ${ }^{\mathrm{TM}}$ diffusion chamber compared to PAA nanoparticles. In another study, pulsed-gradient spinecho nuclear magnetic resonance was utilized to determine penetration capability of PAA particles conjugated with bromelain or papain(144). Bromelain-PAA, papain-PAA, and PAA particles had diffusion coefficients of $7.6 \times 10^{11}, 6.0 \times 10^{11}$, and $2.8 \times 10^{11} \mu \mathrm{m}^{2} / \mathrm{s}$, respectively. The higher diffusion coefficient of bromelain-PAA compared to papain-PAA particles was attributed to higher bromelain vs. papain loading efficiency (10.2 vs. 9.8 
$\mathrm{nmol} / \mathrm{mg}$ ) and activity ( 63.31 vs. $42.21 \%$ of free native bromelain or papain enzyme activity). Papain was also loaded in SNEDDS to improve mucus penetration(145). Labrafac $^{\mathrm{TM}}$ as oil and Cremophor EL as surfactant were used to produce $~ 95 \mathrm{~nm}$ SNEDDS. Papain-SNEDDS had a 2-fold increase in porcine intestinal mucus permeation compared to SNEDDS, as measured via rotating tube method.

\subsection{Dosing Formulation Properties}

Drug formulation properties, such as dosing volume, $\mathrm{pH}$, and ionic strength, can also have a large impact on mucus penetration. When high volume solutions were delivered by oral gavage or direct injection into intestinal loops, particles were able to penetrate deeper into intestinal crypts due to tissue distension compared to low volume gavage solutions(146). Furthermore, when formulations are dosed in high volumes, both MPP (PS/PEG) and mucoadhesive PS particles had similar distribution and penetration, indicating dosing volume had a more significant effect than particle surface functionalization.

Formulation properties, such as osmolarity, can be modulated to enhance delivery through the mucus barrier. Within 10 minutes of intravaginal administration of hypotonic (absorption-inducing) particle solutions (100 nm PS/PEG, 20-220 mOsm/kg), particle retention ( 53\%), distribution, and coverage were significantly increased as compared to particles delivered in isotonic solutions $(294 \mathrm{mOsm} / \mathrm{kg})(147)$. Vaginal epithelium coverage increased from $60 \%$ to $90 \%$ as osmolarity decreased from 294 to $20 \mathrm{mOsm} / \mathrm{kg}$. Dosing hypotonic solutions of doxorubicin, a chemotherapy drug, also resulted in increased vaginal epithelium coverage ( $\sim 60 \%$ ) and absorption (2-fold) compared to isotonic solutions(147). When dosed intrarectally, hypotonic solutions again aided in particle distribution and absorption compared to isotonic solutions (350-450 mOsm). Conversely, hypertonic solutions caused fluid secretion and bowel distension, resulting in particles being primarily located in the lumen. Hypertonic solution (2200 mOsm) have been reported to result in increased drug uptake, however, these increases were attributed to epithelial distention and disruption $(148 ; 149)$. It is apparent that drug formulation properties can impact particle diffusion and thus are important to consider when optimizing delivery systems for overcoming the mucus barrier.

\section{Summary}

Mucus barrier properties are important to consider in designing effective systems for drug delivery to underlying epithelium, and also in understanding microbe interactions with and transport through mucus, and its significance in health and disease. These barrier properties depend on composition (e.g., protein, lipid, and salt concentrations) and structure (e.g., pore size), which can be dynamically altered in response to endogenous and exogenous stimuli, as well as changes in different disease states. As highlighted in this review, these stimuli can include factors that bind mucus components to increase mucus cross-links and viscosity, stimulate protein secretion, and/or inhibit pathogenic colonization. On the other hand, enzymes secreted by the host, viruses, and microbes can degrade the mucus layer by cleaving oligosaccharides or the mucin protein backbone; or disrupting inter- or intramolecular interactions, thus decreasing mucus viscosity. Understanding the mechanisms 
by which mucus provides a selective barrier, and how this barrier changes, for example with exposure to enzymes, food components, microbes and viruses in normal physiological function and with disease, can motivate rational approaches to engineer a mucosal barrier which facilitates efficient drug delivery and promotes a healthy microbiome.

Drug carriers can be strategically designed to adhere to or penetrate through the mucus layer. In evaluating approaches to permeabilize the mucus barrier, it is important to consider potential impact of compromising the integrity of the mucus gel. This could expose the underlying tissues to microbes, viruses, and exogenous factors/or exogenous factors (e.g., luminal contents in the intestine). Continued research on the mechanisms by which mucus provides an effective barrier and mechanisms by which this barrier can be modulated will motivate rational approaches to engineering this natural hydrogel to benefit health and mitigate disease.

\section{Citations}

1. Taniguchi T, Woodward AM, Magnelli P, McColgan NM, Lehoux S, et al. 2017 N-glycosylation affects the stability and barrier function of the MUC16 mucin. Journal of Biological Chemistry 292:11079-90 [PubMed: 28487369]

2. Cone R 2005 Mucus. In Mucosal Immunology, 3rd ed Amsterdam: Elsevier Academic Press 49-72.

3. Carlstedt I, Lindgren H, Sheehan JK, Ulmsten U, Wingerup L. 1983 Isolation and characterization of human cervical-mucus glycoproteins. Biochemical Journal 211:13-22 [PubMed: 6409086]

4. Thomsson KA, Karlsson H, Hansson GC. 2000 Sequencing of sulfated oligosaccharides from mucins by liquid chromatography and electrospray ionization tandem mass spectrometry. Analytical Chemistry 72:4543-9 [PubMed: 11028608]

5. Boat TFCP, Leigh MW. 1994 Biochemistry of mucus In Airway secretion, ed. Takishima T and Shimura S:217-82. New York: Marcel Dekker Number of 217-82

6. Bergstrom KSB, Kissoon-Singh V, Gibson DL, Ma C, Montero M, et al. 2010 Muc2 protects against lethal infectious colitis by disassociating pathogenic and commensal bacteria from the colonic mucosa. PLOS Pathogens 6:e1000902 [PubMed: 20485566]

7. Kamada N, Kim Y-G, Sham HP, Vallance BA, Puente JL, et al. 2012 Regulated virulence controls the ability of a pathogen to compete with the gut microbiota. Science 336:1325-9 [PubMed: 22582016]

8. Lai SK, Wang YY, Hida K, Cone R, Hanes J. 2011 Nanoparticles reveal that human cervicovaginal mucus is riddled with pores larger than viruses. Proceedings of the National Academy of Sciences of the United States of America 108:14371

9. Lehr CMPF, Junginger HE, Tukker JJ. 1991 An estimate of turnover time of intestinal mucus gel layer in the rat in situ loop. International Journal of Pharmaceutics 70:235-40

10. Krishnamoorthy R, Mitra AK. 1998 Prodrugs for nasal drug delivery. Advanced Drug Delivery Reviews 29:135-46 [PubMed: 10837584]

11. Illum L 2003 Nasal drug delivery-possibilities, problems and solutions. Journal of Controlled Release 87:187-98 [PubMed: 12618035]

12. Holmén Larsson JM, Thomsson KA, Rodríguez-Piñeiro AM, Karlsson H, Hansson GC. 2013 Studies of mucus in mouse stomach, small intestine, and colon. III. Gastrointestinal Muc5ac and Muc2 mucin O-glycan patterns reveal a regiospecific distribution. American Journal of Physiology - Gastrointestinal and Liver Physiology 305:G357-63 [PubMed: 23832516]

13. Schwegmann C, Zimmer G, Yoshino T, Enss M-L, Herrler G. 2001 Comparison of the sialic acid binding activity of transmissible gastroenteritis coronavirus and E. coli K99. Virus Research 75:69-73 [PubMed: 11311429] 
14. Ryan PA, Pancholi V, Fischetti VA. 2001 Group A streptococci bind to mucin and human pharyngeal cells through sialic acid-containing receptors. Infection and Immunity 69:7402-12 [PubMed: 11705914]

15. Stanley RA, Ram SP, Wilkinson RK, Roberton AM. 1986 Degradation of pig gastric and colonic mucins by bacteria isolated from the pig colon. Applied and Environmental Microbiology 51:1104-9 [PubMed: 2873788]

16. Tailford LE, Crost EH, Kavanaugh D, Juge N. 2015 Mucin glycan foraging in the human gut microbiome. Frontiers in Genetics 6:81 [PubMed: 25852737]

17. Wolf D, Blasco L, Khan M, Litt M 1977 Human cervical mucus. II. Changes in viscoelasticity during the ovulatory mentrual cycle. Fertility and Sterility 28:47-52 [PubMed: 832715]

18. Allen A 1978 Structure of gastrointestinal mucus glycoproteins and the viscous and gel-forming properties of mucus. Br. Med. Bull. 34:28-33 [PubMed: 342045]

19. Murty VLN, Sarosiek J, Slomiany A, Slomiany BL. 1984 Effect of lipids and proteins on the viscosity of gastric mucus glycoprotein. Biochemical and Biophysical Research Communications 121:521-9 [PubMed: 6732822]

20. Macierzanka A, Mackie AR, Bajka BH, Rigby NM, Nau F, Dupont D. 2014 Transport of particles in intestinal mucus under simulated infant and adult physiological conditions: impact of mucus structure and extracellular DNA. PLOS ONE 9:e95274 [PubMed: 24755941]

21. Bhaskar KR, Gong DH, Bansil R, Pajevic S, Hamilton JA, et al. 1991 Profound increase in viscosity and aggregation of pig gastric mucin at low $\mathrm{pH}$. American Journal of Physiology Gastrointestinal and Liver Physiology 261:G827-32

22. Wolf DPSJ, Khan MA, Litt M. 1977 Human cervical mucus. III. Isolation and characterization of rheologically active mucin. Fertility Sterility 28:53-8 [PubMed: 832716]

23. Thim L, Madsen F, Poulsen SS. 2002 Effect of trefoil factors on the viscoelastic properties of mucus gels. European Journal of Clinical Investigation 32:519-27 [PubMed: 12153553]

24. Bastholm SK, Samson MH, Becher N, Hansen LK, Stubbe PR, et al. 2017 Trefoil factor peptide 3 is positively correlated with the viscoelastic properties of the cervical mucus plug. Acta Obstetricia et Gynecologica Scandinavica 96:47-52 [PubMed: 27731893]

25. Krimi RB, Kotelevets L, Dubuquoy L, Plaisancié P, Walker F, et al. 2008 Resistin-like molecule $\beta$ regulates intestinal mucous secretion and curtails TNBS-induced colitis in mice. Inflammatory Bowel Diseases 14:931-41 [PubMed: 18300276]

26. Yu H, He Y, Zhang X, Peng Z, Yang Y, et al. 2011 The rat IgGFc $\gamma$ BP and Muc2 C-terminal domains and TFF3 in two intestinal mucus layers bind together by covalent interaction. PLOS ONE 6:e20334 [PubMed: 21629776]

27. Creeth JM, Bridge JL, Horton JR. 1979 An interaction between lysozyme and mucus glycoproteins. Implications for density-gradient separations. Biochemical Journal 181:717-24 [PubMed: 518551]

28. Ellison RT, Giehl TJ. 1991 Killing of gram-negative bacteria by lactoferrin and lysozyme. Journal of Clinical Investigation 88:1080-91 [PubMed: 1918365]

29. Actor JK, Hwang S-A, Kruzel ML. 2009 Lactoferrin as a natural immune modulator. Current Pharmaceutical Design 15:1956-73 [PubMed: 19519436]

30. Jenssen AOA Harbitz O,A Smidsrød O. 1978 Viscometric and chemical characterization of sputum from patients with chronic obstructive lung disease. Scandinavian Journal of Respiratory Diseases 59:141-53 [PubMed: 28562]

31. Fahrbach KM, Malykhina O, Stieh DJ, Hope TJ. 2013 Differential binding of IgG and IgA to mucus of the female reproductive tract. PLOS ONE 8:e76176 [PubMed: 24098437]

32. Wang YY, Kannan A, Nunn KL, Murphy MA, Subramani DB, et al. 2014 IgG in cervicovaginal mucus traps HSV and prevents vaginal Herpes infections. Mucosal Immunol 7:1036-44 [PubMed: 24496316]

33. Ovesen L, Bendtsen F, Tage-Jensen U, Pedersen NT, Gram BR, Rune SJ. 1986 Intraluminal pH in the stomach, duodenum, and proximal jejunum in normal subjects and patients with exocrine pancreatic insufficiency. Gastroenterology 90:958-62 [PubMed: 3949122]

34. Lieleg O, Vladescu I, Ribbeck K. 2010 Characterization of particle translocation through mucin hydrogels. Biophysical Journal 98:1782-9 [PubMed: 20441741] 
35. Celli JP, Turner BS, Afdhal NH, Ewoldt RH, McKinley GH, et al. 2007 Rheology of gastric mucin exhibits a pH-dependent sol-gel transition. Biomacromolecules 8:1580-6 [PubMed: 17402780]

36. Bansil R, Turner BS. 2006 Mucin structure, aggregation, physiological functions and biomedical applications. Current Opinion in Colloid \& Interface Science 11:164-70

37. Johansson ME, Gustafsson JK, Holmen-Larsson J, Jabbar KS, Xia L, et al. 2014 Bacteria penetrate the normally impenetrable inner colon mucus layer in both murine colitis models and patients with ulcerative colitis. Gut 63:281-91 [PubMed: 23426893]

38. Duncan GA, Jung J, Joseph A, Thaxton AL, West NE, et al. 2016 Microstructural alterations of sputum in cystic fibrosis lung disease. JCI Insight 1:e88198 [PubMed: 27812540]

39. Serisier DJ, Carroll MP, Shute JK, Young SA. 2009 Macrorheology of cystic fibrosis, chronic obstructive pulmonary disease \& normal sputum. Respiratory Research 10:63 [PubMed: 19580650]

40. Matsui H, Wagner VE, Hill DB, Schwab UE, Rogers TD, et al. 2006 A physical linkage between cystic fibrosis airway surface dehydration and Pseudomonas aeruginosa biofilms. Proceedings of the National Academy of Sciences of the United States of America 103:18131-6 [PubMed: 17116883]

41. Chen S-J, Liu X-W, Liu J- P, Yang X-Y, Lu F-G. 2014 Ulcerative colitis as a polymicrobial infection characterized by sustained broken mucus barrier. World Journal of Gastroenterology 20:9468-75 [PubMed: 25071341]

42. Pullan RD, Thomas GA, Rhodes M, Newcombe RG, Williams GT, et al. 1994 Thickness of adherent mucus gel on colonic mucosa in humans and its relevance to colitis. Gut 35:353-9 [PubMed: 8150346]

43. Braun A, Treede I, Gotthardt D, Tietje A, Zahn A, et al. 2009 Alterations of phospholipid concentration and species composition of the intestinal mucus barrier in ulcerative colitis: A clue to pathogenesis. Inflammatory Bowel Diseases 15:1705-20 [PubMed: 19504612]

44. Corfield AP, Myerscough N, Bradfield N, Do Amaral Corfield C, Gough M, et al. 1996 Colonic mucins in ulcerative colitis: evidence for loss of sulfation. Glycoconjugate Journal 13:809-22 [PubMed: 8910008]

45. McElroy SJ, Prince LS, Weitkamp J-H, Reese J, Slaughter JC, Polk DB. 2011 Tumor necrosis factor receptor 1-dependent depletion of mucus in immature small intestine: a potential role in neonatal necrotizing enterocolitis. American Journal of Physiology. Gastrointestinal and Liver Physiology 301:G656-66 [PubMed: 21737776]

46. Israel E 1994 Neonatal necrotizing enterocolitis, a disease of the immature intestinal mucosal barrier. Acta Pædiatrica 83:27-32

47. Vieten D, Corfield A, Carroll D, Ramani P, Spicer R. 2005 Impaired mucosal regeneration in neonatal necrotising enterocolitis. Pediatric Surgery International 21:153-60 [PubMed: 15578191]

48. Coutinho HB, da Mota HC, Coutinho VB, Robalinho TI, Furtado AF, et al. 1998 Absence of lysozyme (muramidase) in the intestinal Paneth cells of newborn infants with necrotising enterocolitis. Journal of Clinical Pathology 51:512-4 [PubMed: 9797727]

49. Hills BA. 1996 Gastric surfactant and the hydrophobic mucosal barrier. Gut 39:621-4 [PubMed: 9026472]

50. Tytgat GNJ. 2011 Etiopathogenetic principles and peptic ulcer disease classification. Digestive Diseases 29:454-8 [PubMed: 22095009]

51. Kerss S, Allen A, Garner A. 1982 A simple method for measuring thickness of the mucus gel layer adherent to rat, frog and human gastric mucosa: influence of feeding, prostaglandin, Nacetylcysteine and other agents. Clinical Science 63:187-95 [PubMed: 6806004]

52. Pearson JP, Ward R, Allen A, Roberts NB, Taylor WH. 1986 Mucus degradation by pepsin: comparison of mucolytic activity of human pepsin 1 and pepsin 3: implications in peptic ulceration. Gut 27:243-8 [PubMed: 3084340]

53. Lichtenberger L, Wang Z-M, Romero J, Ulloa C, Perez J, et al. 1995 Non-steroidal antiinflammatory drugs (NSAIDs) associate with zwitterionic phospholipids: Insight into the mechanism and reversal of NSAID-induced gastrointestinal injury. Nature Medicine 1:154-8 
54. Hoegger MJ, Fischer AJ, McMenimen JD, Ostedgaard LS, Tucker AJ, et al. 2014 Impaired mucus detachment disrupts mucociliary transport in a piglet model of cystic fibrosis. Science (New York, N.Y.) 345:818-22

55. Dische Z, Sant Agnese Pd, Pallavicini C, Youlos J. 1959 Composition of mucoprotein fractions from duodenal fluid of patients with cystic fibrosis of the pancreas and from controls. Pediatrics 24:74-91 [PubMed: 13667337]

56. Boat TF, Cheng PW, Iyer RN, Carlson DM, Polony I. 1976 Human respiratory tract secretions. Archives of Biochemistry and Biophysics 177:95-104 [PubMed: 999298]

57. Potter JL, Matthews LW, Spector S, Lemm J. 1967 Studies on pulmonary secretions. II. Osmolality and the ionic environment of pulmonary secretions from patients with cystic fibrosis, bronchiectasis, and laryngectomy. The American Review of Respiratory Disease 96:83-7 [PubMed: 6027728]

58. Slomiany A, Murty VLN, Aono M, Snyder CE, Herp A, Slomiany BL. 1982 Lipid composition of tracheobronchial secretions from normal individuals and patients with cystic fibrosis. Biochimica et Biophysica Acta (BBA) - Lipids and Lipid Metabolism 710:106-11 [PubMed: 7055590]

59. Kopito LE, Kosasky HJ, Shwachman H. 1973 Water and electrolytes in cervical mucus from patients with cystic fibrosis. Fertility and Sterility 24:512-6 [PubMed: 4715225]

60. Baconnais S, Tirouvanziam R, Zahm J-M, de Bentzmann S, Péault B, et al. 1999 Ion composition and rheology of airway liquid from cystic fibrosis fetal tracheal xenografts. American Journal of Respiratory Cell and Molecular Biology 20:605-11 [PubMed: 10100991]

61. Suk JS, Lai SK, Wang Y-Y, Ensign LM, Zeitlin PL, et al. 2009 The penetration of fresh undiluted sputum expectorated by cystic fibrosis patients by non-adhesive polymer nanoparticles. Biomaterials 30:2591-7 [PubMed: 19176245]

62. Schuster BS, Suk JS, Woodworth GF, Hanes J. 2013 Nanoparticle diffusion in respiratory mucus from humans without lung disease. Biomaterials 34:3439-46 [PubMed: 23384790]

63. Aslam A, Spicer RD, Corfield AP. 1998 Turnover of radioactive mucin precursors in the colon of patients with Hirschsprung's disease correlates with the development of enterocolitis. Journal of Pediatric Surgery 33:103-5 [PubMed: 9473111]

64. Teitelbaum DH, Caniano DA, Qualman SJ. 1989 The pathophysiology of Hirschsprung'sassociated enterocolitis: importance of histologic correlates. Journal of Pediatric Surgery 24:12717 [PubMed: 2593059]

65. Yildiz HM, Carlson TL, Goldstein AM, Carrier RL. 2015 Mucus barriers to microparticles and microbes are altered in Hirschsprung's disease. Macromolecular Bioscience 15:712-8 [PubMed: 25644515]

66. Fujimoto T, Puri P. 1988 Persistence of enterocolitis following diversion of faecal stream in Hirschsprung's disease. Pediatric Surgery International 3:141-6

67. Lewis WG, Robinson LS, Gilbert NM, Perry JC, Lewis AL. 2013 Degradation, foraging, and depletion of mucus sialoglycans by the vagina-adapted Actinobacterium Gardnerella vaginalis. The Journal of Biological Chemistry 288:12067-79 [PubMed: 23479734]

68. Olmsted SS, Meyn LA, Rohan LC, Hillier SL. 2003 Glycosidase and proteinase activity of anaerobic gram-negative bacteria isolated from women with bacterial vaginosis. Sexually Transmitted Diseases 30:257-61 [PubMed: 12616147]

69. Ruas-Madiedo P, Gueimonde M, Fernandez-Garcia M, de los Reyes-Gavilan CG, Margolles A. 2008 Mucin degradation by Bifidobacterium strains isolated from the human intestinal microbiota. Applied and Environmental Microbiology 74:1936-40 [PubMed: 18223105]

70. Celli JP, Turner BS, Afdhal NH, Keates S, Ghiran I, et al. 2009 Helicobacter pylori moves through mucus by reducing mucin viscoelasticity. Proceedings of the National Academy of Sciences of the United States 106:14321-6

71. Cohen M, Zhang X-Q, Senaati HP, Chen H-W, Varki NM, et al. 2013 Influenza A penetrates host mucus by cleaving sialic acids with neuraminidase. Virology Journal 10:321 [PubMed: 24261589]

72. Olmsted SS, Padgett JL, Yudin AI, Whaley KJ, Moench TR, Cone RA. 2001 Diffusion of macromolecules and virus-like particles in human cervical mucus. Biophysical Journal 81:1930-7 [PubMed: 11566767] 
73. Yildiz H, Speciner L, Ozdemir C, Cohen D, Carrier R. 2015 Food-associated stimuli enhance barrier properties of gastrointestinal mucus. Biomaterials 54:1-8 [PubMed: 25907034]

74. Sircar S, Keener JP, Fogelson AL. 2013 The effect of divalent vs. monovalent ions on the swelling of mucin-like polyelectrolyte gels: Governing equations and equilibrium analysis. The Journal of Chemical Physics 138

75. Davies HS, Pudney PDA, Georgiades P, Waigh TA, Hodson NW, et al. 2014 Reorganisation of the salivary mucin network by dietary components: Insights from green tea polyphenols. PLOS ONE 9:e108372 [PubMed: 25264771]

76. Poulsen SS, Kissow H, Hare K, Hartmann B, Thim L. 2005 Luminal and parenteral TFF2 and TFF3 dimer and monomer in two models of experimental colitis in the rat. Regulatory Peptides 126:163-71 [PubMed: 15664663]

77. Herrmann K, Carroll K. 2014 An exclusively human milk diet reduces necrotizing enterocolitis. Breastfeeding Medicine 9:184-90 [PubMed: 24588561]

78. Scaldaferri F, Lopetuso LR, Petito V, Cufino V, Bilotta M, et al. 2014 Gelatin tannate ameliorates acute colitis in mice by reinforcing mucus layer and modulating gut microbiota composition: Emerging role for 'gut barrier protectors' in IBD? United European Gastroenterology Journal 2:113-22 [PubMed: 24918016]

79. Lai SK, Wang Y-Y, Cone R, Wirtz D, Hanes J. 2009 Altering mucus rheology to "solidify" human mucus at the nanoscale PLOS ONE 4:e4294 [PubMed: 19173002]

80. McCool DJ, Forstner JF, Forstner GG. 1995 Regulated and unregulated pathways for MUC2 mucin secretion in human colonic LS180 adenocarcinoma cells are distinct. Biochemical Journal 312:125-33 [PubMed: 7492301]

81. Epple HJ, Kreusel KM, Hanski C, Schulzke JD, Riecken EO, Fromm M. 1997 Differential stimulation of intestinal mucin secretion by cholera toxin and carbachol. Pflügers Archiv 433:63847 [PubMed: 9049150]

82. Specian RD, Neutra MR. 1980 Mechanism of rapid mucus secretion in goblet cells stimulated by acetylcholine. The Journal of Cell Biology 85:626-40 [PubMed: 7391135]

83. Mian N, Anderson CE, Pope AJ, Smith AR, Richardson PS, et al. 1982 Directional Ca2+ effect on stimulation of mucin secretion from chicken trachea in vitro. Biochemical Journal 208:425-33 [PubMed: 7159411]

84. Zalewsky CA, Moody FG, Allen M, Davis EK. 1983 Stimulation of canine gastric mucus secretion with intraarterial acetylcholine chloride. Gastroenterology 85:1067-75 [PubMed: 6618101]

85. Trout L, Gatzy JT, Ballard ST. 1998 Acetylcholine-induced liquid secretion by bronchial epithelium: role of Cl- and HCO3- transport. American Journal of Physiology - Lung Cellular and Molecular Physiology 275:L1095-9

86. Rubinstein A, Tirosh B. 1994 Mucus gel thickness and turnover in the gastrointestinal tract of the rat: Response to cholinergic stimulus and implication for mucoadhesion. Pharmaceutical Research 11:794-9 [PubMed: 7937516]

87. McCool DJ, Marcon MA, Forstner JF, Forstner GG. 1990 The T84 human colonic adenocarcinoma cell line produces mucin in culture and releases it in response to various secretagogues. Biochemical Journal 267:491-500 [PubMed: 2110452]

88. Majewski M, Sarosiek I, Wallner G, Edlavitch SA, Sarosiek J. 2014 Stimulation of mucin, mucus, and viscosity during lubiprostone in patients with chronic constipation may potentially lead to increase of lubrication. Clinical and Translational Gastroenterology 5:e66 [PubMed: 25521039]

89. Barcelo A, Claustre J, Moro F, Chayvialle JA, Cuber JC, Plaisancié P. 2000 Mucin secretion is modulated by luminal factors in the isolated vascularly perfused rat colon. Gut 46:218-24 [PubMed: 10644316]

90. Shimotoyodome A, Meguro S, Hase T, Tokimitsu I, Sakata T. 2000 Short chain fatty acids but not lactate or succinate stimulate mucus release in the rat colon. Comparative Biochemistry and Physiology Part A: Molecular \& Integrative Physiology 125:525-31

91. Benoit B, Bruno J, Kayal F, Estienne M, Debard C, et al. 2015 Saturated and unsaturated fatty acids differently modulate colonic goblet cells In vitro and in rat pups. The Journal of Nutrition 145:1754-62 [PubMed: 26108543] 
92. Wlodarska M, Willing BP, Bravo DM, Finlay BB. 2015 Phytonutrient diet supplementation promotes beneficial Clostridia species and intestinal mucus secretion resulting in protection against enteric infection. Scientific Reports 5:9253 [PubMed: 25787310]

93. Benoit B, Laugerette F, Plaisancié P, Géloën A, Bodennec J, et al. 2015 Increasing fat content from 20 to $45 \mathrm{wt} \%$ in a complex diet induces lower endotoxemia in parallel with an increased number of intestinal goblet cells in mice. Nutrition Research 35:346-56 [PubMed: 25687164]

94. Saxena A, Baliga MS, Ponemone V, Kaur K, Larsen B, et al. 2013 Mucus and adiponectin deficiency: role in chronic inflammation-induced colon cancer. International journal of colorectal disease 28:1267-79 [PubMed: 23474825]

95. Plaisancie P, Ducroc R, Homsi ME, Tsocas A, Guilmeau S, et al. 2006 Luminal leptin activates mucin-secreting goblet cells in the large bowel. American Journal of Physiology - Gastrointestinal and Liver Physiology 290:G805-12 [PubMed: 16455789]

96. van Es JH, van Gijn ME, Riccio O, van den Born M, Vooijs M, et al. 2005 Notch/[gamma]secretase inhibition turns proliferative cells in intestinal crypts and adenomas into goblet cells. Nature 435:959-63 [PubMed: 15959515]

97. Monk JM, Lepp D, Zhang CP, Wu W, Zarepoor L, et al. 2016 Diets enriched with cranberry beans alter the microbiota and mitigate colitis severity and associated inflammation. The Journal of Nutritional Biochemistry 28:129-39 [PubMed: 26878790]

98. Servin AL. 2004 Antagonistic activities of lactobacilli and bifidobacteria against microbial pathogens. Federation of European Microbiological Societies Microbiology Reviews 28:405-40

99. Jones SE, Versalovic J. 2009 Probiotic Lactobacillus reuteri biofilms produce antimicrobial and anti-inflammatory factors. BioMed Central Microbiology 9:35- [PubMed: 19210794]

100. Silva SD, Robbe-Masselot C, Ait-Belgnaoui A, Mancuso A, Mercade-Loubière M, et al. 2014 Stress disrupts intestinal mucus barrier in rats via mucin \&lt;em\&gt;O\&lt;/em\&gt;-glycosylation shift: prevention by a probiotic treatment. American Journal of Physiology - Gastrointestinal and Liver Physiology 307:G420-9 [PubMed: 24970779]

101. Caplan MS, Miller-Catchpole $\dagger \neq \mathrm{R}$, Kaup§ S, Russell* T, et al. 1999 Bifidobacterial supplementation reduces the incidence of necrotizing enterocolitis in a neonatal rat model. Gastroenterology 117:577-83 [PubMed: 10464133]

102. Mack DR, Ahrne S, Hyde L, Wei S, Hollingsworth MA. 2003 Extracellular MUC3 mucin secretion follows adherence of Lactobacillus strains to intestinal epithelial cells in vitro. Gut 52:827-33 [PubMed: 12740338]

103. Toumi R, Abdelouhab K, Rafa H, Soufli I, Raissi-Kerboua D, et al. 2013 Beneficial role of the probiotic mixture Ultrabiotique on maintaining the integrity of intestinal mucosal barrier in DSSinduced experimental colitis. Immunopharmacology and Immunotoxicology 35:403-9 [PubMed: 23638770]

104. Klu YAK, Chen J. 2016 Influence of probiotics, included in peanut butter, on the fate of selected Salmonella and Listeria strains under simulated gastrointestinal conditions. Journal of Applied Microbiology 120:1052-60 [PubMed: 26836043]

105. Ocaña VS, Pesce de Ruiz Holgado AA, Nader-Macías ME. 1999 Selection of vaginal H2O2generating Lactobacillus species for probiotic use. Current Microbiology 38:279-84 [PubMed: 10355116]

106. Müller C, Leithner K, Hauptstein S, Hintzen F, Salvenmoser W, Bernkop-Schnürch A. 2013 Preparation and characterization of mucus-penetrating papain/poly(acrylic acid) nanoparticles for oral drug delivery applications. An Interdisciplinary Forum for Nanoscale Science and Technology 15:1-13

107. Shak S, Capon DJ, Hellmiss R, Marsters SA, Baker CL. 1990 Recombinant human DNase I reduces the viscosity of cystic fibrosis sputum. Proceedings of the National Academy of Sciences of the United States of America 87:9188-92 [PubMed: 2251263]

108. Suk JS, Lai SK, Boylan NJ, Dawson MR, Boyle MP, Hanes J. 2011 Rapid transport of muco-inert nanoparticles in cystic fibrosis sputum treated with $\mathrm{N}$-acetyl cysteine. Nanomedicine 6:365-75 [PubMed: 21385138]

109. Rubin BK. 2007 Mucolytics, expectorants, and mucokinetic medications. Respiratory Care 52:859-65 [PubMed: 17594730] 
110. Seagrave J, Albrecht HH, Hill DB, Rogers DF, Solomon G. 2012 Effects of guaifenesin, Nacetylcysteine, and ambroxol on MUC5AC and mucociliary transport in primary differentiated human tracheal-bronchial cells. Respiratory Research 13:606-14

111. Rogers DF. 2007 Mucoactive agents for airway mucus hypersecretory diseases. Respiratory Care 52:1176-93 [PubMed: 17716385]

112. Morgenroth K 1985 Morphology of the bronchial lining layer and its alteration in IRDS, ARDS and COLD. European Journal of Respiratory Diseases 142:7-18 [PubMed: 3860398]

113. Hooper C, Calvert J. 2008 The role for S-carboxymethylcysteine (carbocisteine) in the management of chronic obstructive pulmonary disease. International Journal of Chronic Obstructive Pulmonary Disease 3:659-69 [PubMed: 19281081]

114. Braga PC, Allegra L, Rampoldi C, Ornaghi A, Beghi G. 1990 Long-lasting effects on rheology and clearance of bronchial mucus after short-term administration of high doses of carbocysteinelysine to patients with chronic bronchitis. Respiration 57:353-8 [PubMed: 2099568]

115. Girod S, Galabert C, Pierrot D, Boissonnade MM, Zahm JM, et al. 1991 Role of phospholipid lining on respiratory mucus clearance by cough. Journal of Applied Physiology 71:2262-6 [PubMed: 1778921]

116. Tam PY, Verdugo P. 1981 Control of mucus hydration as a Donnan equilibrium process. Nature 292:340-2 [PubMed: 7195985]

117. Verdugo P 2012 Supramolecular Dynamics of Mucus. Cold Spring Harbor Perspectives in Medicine 2:a009597 [PubMed: 23125200]

118. Chen EYT, Yang N, Quinton PM, Chin W-C. 2010 A new role for bicarbonate in mucus formation. American Journal of Physiology. Lung Cellular and Molecular Physiology 299:L542_ L9 [PubMed: 20693315]

119. Georgiades P, Pudney PDA, Thornton DJ, Waigh TA. 2014 Particle tracking microrheology of purified gastrointestinal mucins. Biopolymers 101:366-77 [PubMed: 23955640]

120. Chassaing B, Koren O, Goodrich JK, Poole AC, Srinivasan S, et al. 2015 Dietary emulsifiers impact the mouse gut microbiota promoting colitis and metabolic syndrome. Nature 519:92-6 [PubMed: 25731162]

121. Qin X, Deitch EA. 2015 Dissolution of lipids from mucus: A possible mechanism for prompt disruption of gut barrier function by alcohol. Toxicology letters 232:356-62 [PubMed: 25445722]

122. Lai SK, Wang Y-Y, Hida K, Cone R, Hanes J. 2010 Nanoparticles reveal that human cervicovaginal mucus is riddled with pores larger than viruses. Proceedings of the National Academy of Sciences 107:598-603

123. Lai SK, Suk JS, Pace A, Wang Y-Y, Yang M, et al. 2011 Drug carrier nanoparticles that penetrate human chronic rhinosinusitis mucus. Biomaterials 32:6285-90 [PubMed: 21665271]

124. Yildiz HM, McKelvey CA, Marsac PJ, Carrier RL. 2015 Size selectivity of intestinal mucus to diffusing particulates is dependent on surface chemistry and exposure to lipids. Journal of drug targeting 23:768-74 [PubMed: 26453172]

125. Friedl H, Dünnhaupt S, Hintzen F, Waldner C, Parikh S, et al. 2013 Development and evaluation of a novel mucus diffusion test system approved by self-nanoemulsifying drug delivery systems. Journal of Pharmaceutical Sciences 102:4406-13 [PubMed: 24258284]

126. Peppas NA, Buri PA. 1985 Surface, interfacial and molecular aspects of polymer bioadhesion on soft tissues. Journal of Controlled Release 2:257-75

127. Lee JW, Park JH, Robinson JR. 2000 Bioadhesive-based dosage forms: The next generation. Journal of Pharmaceutical Sciences 89:850-66 [PubMed: 10861586]

128. Shaikh R, Raj Singh T, Garland M, Woolfson A, Donnelly R. 2011 Mucoadhesive drug delivery systems. Journal of Pharmacy and Bioallied Sciences 3:89-100 [PubMed: 21430958]

129. Foster SN, Pearson JP, Hutton DA, Allen A, Dettmar PW. 1994 Interaction of polyacrylates with porcine pepsin and the gastric mucus barrier: a mechanism for mucosal protection. Clinical Science 87:719-26 [PubMed: 7874865]

130. Akiyama Y, Nagahara N, Kashihara T, Hirai S, Toguchi H. 1995 In vitro and in vivo evaluation of mucoadhesive microspheres prepared for the gastrointestinal tract using polyglycerol esters of 
fatty acids and a poly(acrylic acid) derivative. An Official Journal of the American Association of Pharmaceutical Scientists 12:397-405

131. Lehr C-M, Bouwstra JA, Tukker JJ, Junginger HE. 1990 Intestinal transit of bioadhesive microspheres in an in situ loop in the rat-A comparative study with copolymers and blends based on poly(acrylic acid). Journal of Controlled Release 13:51-62

132. Bernkop-Schnürch A, Guggi D, Pinter Y. 2004 Thiolated chitosans: development and in vitro evaluation of a mucoadhesive, permeation enhancing oral drug delivery system. Journal of Controlled Release 94:177-86 [PubMed: 14684281]

133. Guggi D, Kast C, Bernkop-Schnürch A. 2003 In vivo evaluation of an oral salmon calcitonindelivery system based on a thiolated chitosan carrier matrix. An Official Journal of the American Association of Pharmaceutical Scientists 20:1989-94

134. Yang M, Lai SK, Wang Y-Y, Zhong W, Happe C, et al. 2011 Biodegradable nanoparticles composed entirely of safe materials that rapidly penetrate human mucus. Angewandte Chemie (International ed. in English) 50:2597-600 [PubMed: 21370345]

135. Tang BC, Dawson M, Lai SK, Wang Y-Y, Suk JS, et al. 2009 Biodegradable polymer nanoparticles that rapidly penetrate the human mucus barrier. Proceedings of the National Academy of Sciences of the United States of America 106:19268-73 [PubMed: 19901335]

136. Wang Y-Y, Lai SK, So C, Schneider C, Cone R, Hanes J. 2011 Mucoadhesive nanoparticles may disrupt the protective human mucus barrier by altering its microstructure. PLOS ONE 6:e21547 [PubMed: 21738703]

137. Yang M, Lai SK, Yu T, Wang Y-Y, Happe C, et al. 2014 Nanoparticle penetration of human cervicovaginal mucus: The effect of polyvinyl alcohol. Journal of Controlled Release : Official Journal of the Controlled Release Society 192:202-8 [PubMed: 25090196]

138. Schneider CS, Xu Q, Boylan NJ, Chisholm J, Tang BC, et al. 2017 Nanoparticles that do not adhere to mucus provide uniform and long-lasting drug delivery to airways following inhalation. Science Advances 3:e1601556 [PubMed: 28435870]

139. Xu Q, Ensign LM, Boylan NJ, Schön A, Gong X, et al. 2015 Impact of surface polyethylene glycol (PEG) density on biodegradable nanoparticle transport in mucus ex vivo and distribution in vivo. ACS nano 9:9217-27 [PubMed: 26301576]

140. Mastorakos P, da Silva AL, Chisholm J, Song E, Choi WK, et al. 2015 Highly compacted biodegradable DNA nanoparticles capable of overcoming the mucus barrier for inhaled lung gene therapy. Proceedings of the National Academy of Sciences of the United States of America 112:8720-5 [PubMed: 26124127]

141. Yu T, Chan KWY, Anonuevo A, Song X, Schuster BS, et al. 2015 Liposome-based mucuspenetrating particles (MPP) for mucosal theranostics: Demonstration of diamagnetic chemical exchange saturation transfer (diaCEST) magnetic resonance imaging (MRI). Nanomedicine : Nanotechnology, Biology, and Medicine 11:401-5

142. Chen S, Li L, Zhao C, Zheng J. 2010 Surface hydration: Principles and applications toward lowfouling/nonfouling biomaterials. Polymer 51:5283-93

143. Shan W, Zhu X, Tao W, Cui Y, Liu M, et al. 2016 Enhanced oral delivery of protein drugs using zwitterion-functionalized nanoparticles to overcome both the diffusion and absorption barriers. ACS Applied Materials and Interfaces 8:25444-53 [PubMed: 27588330]

144. Pereira de Sousa I, Cattoz B, Wilcox MD, Griffiths PC, Dalgliesh R, et al. 2015 Nanoparticles decorated with proteolytic enzymes, a promising strategy to overcome the mucus barrier. European Journal of Pharmaceutics and Biopharmaceutics 97:257-64 [PubMed: 25661320]

145. Leichner C, Menzel C, Laffleur F, Bernkop-Schnürch A. 2017 Development and in vitro characterization of a papain loaded mucolytic self-emulsifying drug delivery system (SEDDS). International Journal of Pharmaceutics 530:346-53 [PubMed: 28782582]

146. Maisel K, Ensign L, Reddy M, Cone R, Hanes J. 2015 Effect of surface chemistry on nanoparticle interaction with gastrointestinal mucus and distribution in the gastrointestinal tract following oral and rectal administration in the mouse. Journal of Controlled Release : Official Journal of the Controlled Release Society 197:48-57 [PubMed: 25449804] 
147. Ensign LM, Hoen T, Maisel K, Cone R, Hanes J. 2013 Enhanced vaginal drug delivery through the use of hypotonic formulations that induce fluid uptake. Biomaterials 34:6922-9 [PubMed: 23769419]

148. Maisel K, Chattopadhyay S, Moench T, Hendrix C, Cone R, et al. 2015 Enema ion compositions for enhancing colorectal drug delivery. Journal of Controlled Release : Official Journal of the Controlled Release Society 209:280-7

149. Leyva FJ, Bakshi RP, Fuchs EJ, Li L, Caffo BS, et al. 2013 Isoosmolar enemas demonstrate preferential gastrointestinal distribution, safety, and acceptability compared with hyperosmolar and hypoosmolar enemas as a potential delivery vehicle for rectal microbicides. AIDS Research and Human Retroviruses 29:1487-95 [PubMed: 23885722]

150. Popov A, Schopf L, Bourassa J, Chen H. 2016 Enhanced pulmonary delivery of fluticasone propionate in rodents by mucus-penetrating nanoparticles. International Journal of Pharmaceutics 502:188-97 [PubMed: 26902722] 


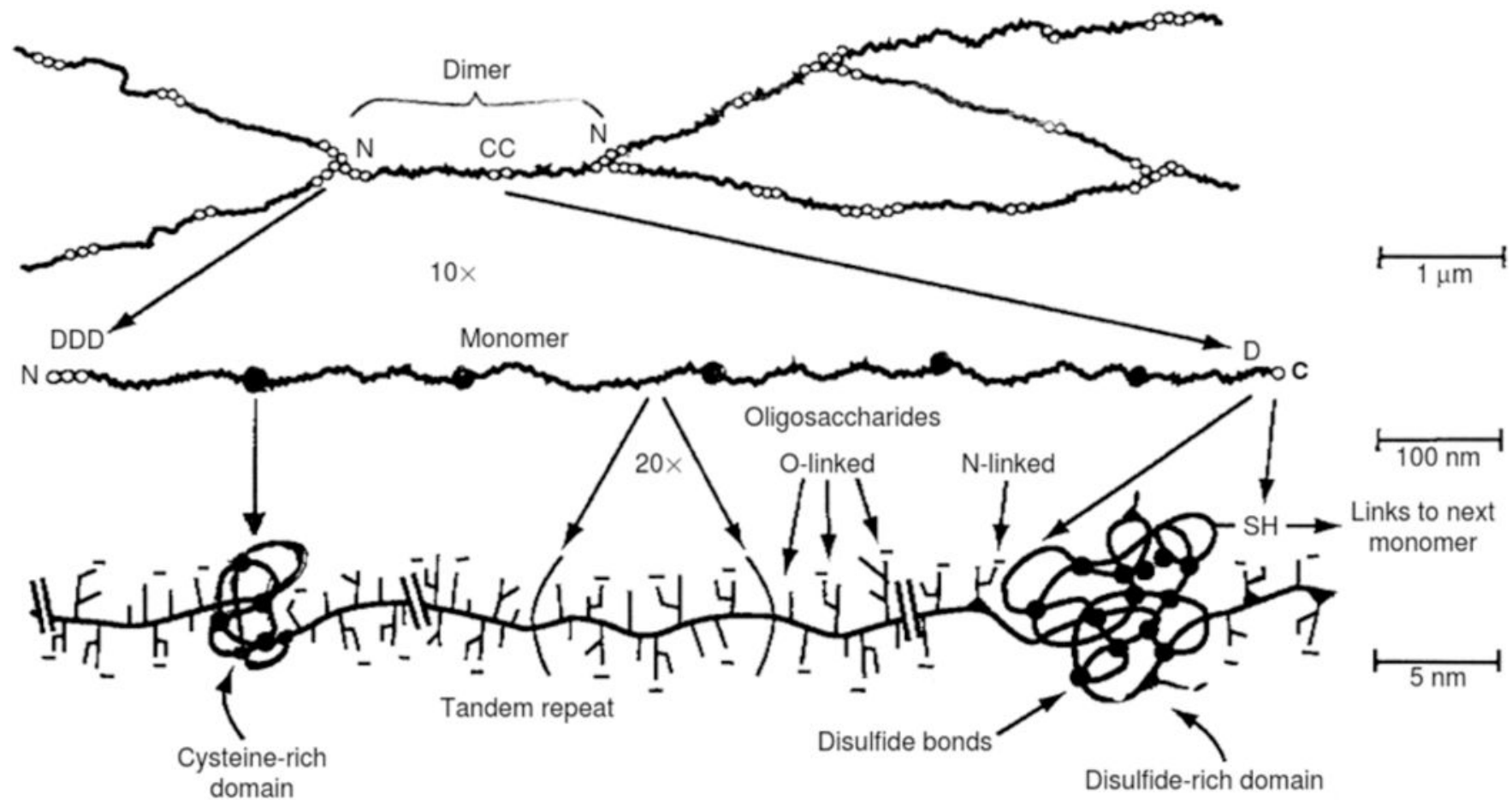

Figure 1.

Hierarchical structure of gel-forming mucins. Adapted from (2). 

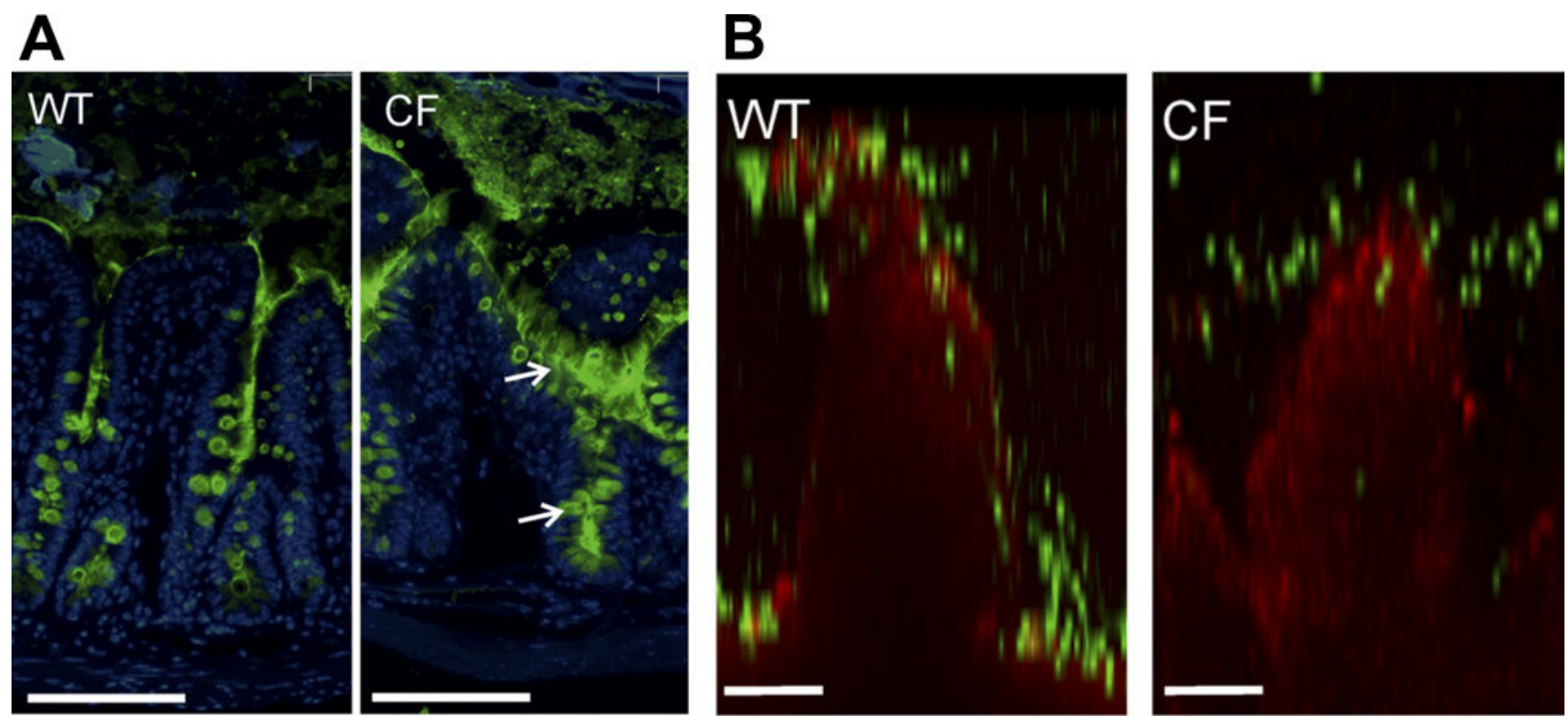

Figure 2.

Increased mucus amount in Cystic Fibrosis (CF, $\mathrm{Cftr} \Delta \mathrm{F} 508$ mouse) compared to wildtype (WT). (A) Mucus distribution in ileum of WT and CF mice immunostained for Muc2 (green) and nuclei (blue). Arrows point to mucus attached to goblet cells. Scale bars $=100$ $\mu \mathrm{m}$. (B) Representative confocal images of WT and CF villi (red) overlaid with $2 \mu \mathrm{m}$ particles (green). Scale bars $=50 \mu \mathrm{m}$. Adapted from (37). 


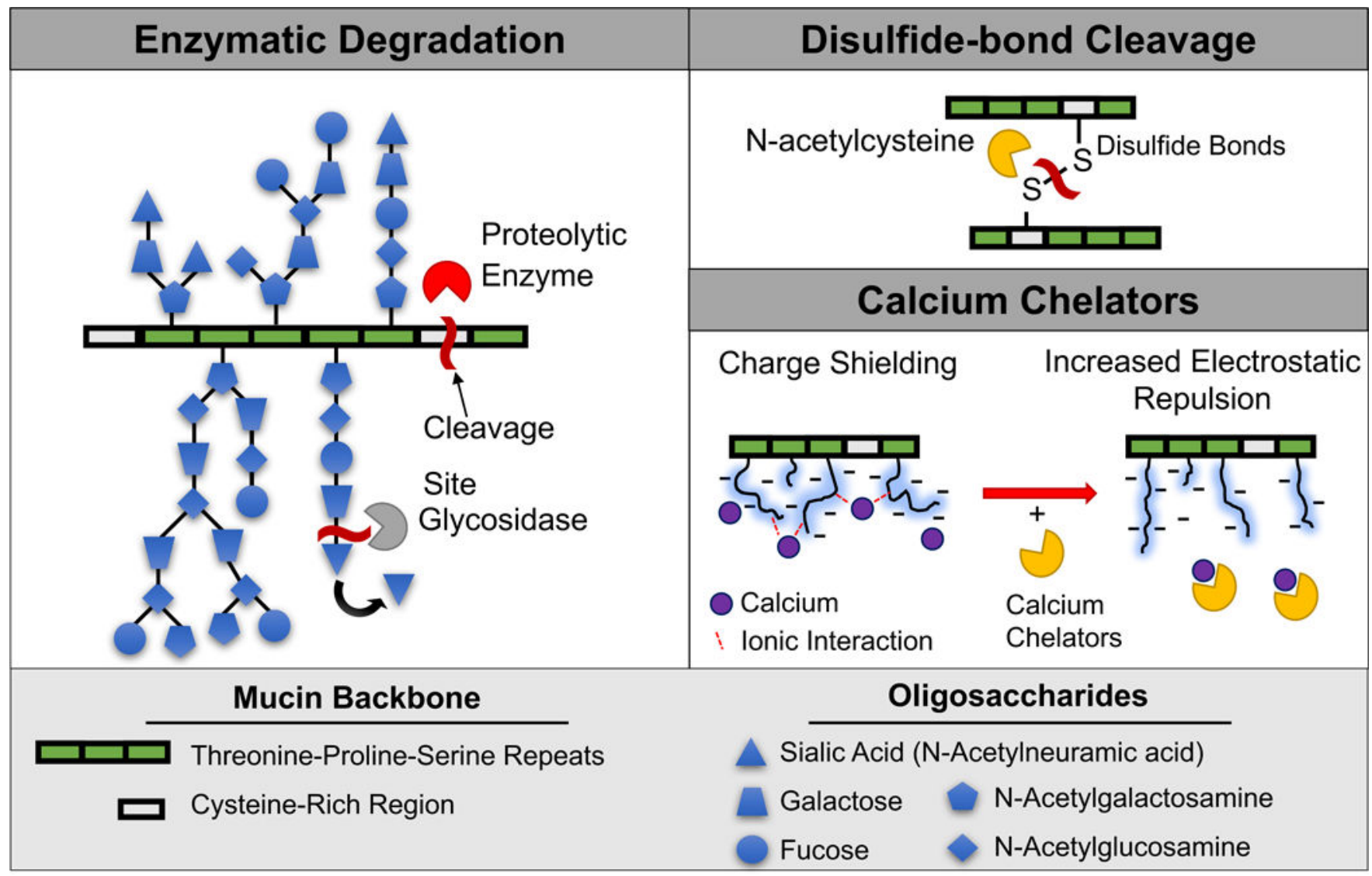

Figure 3.

Methods to break down mucin structure. 
Water

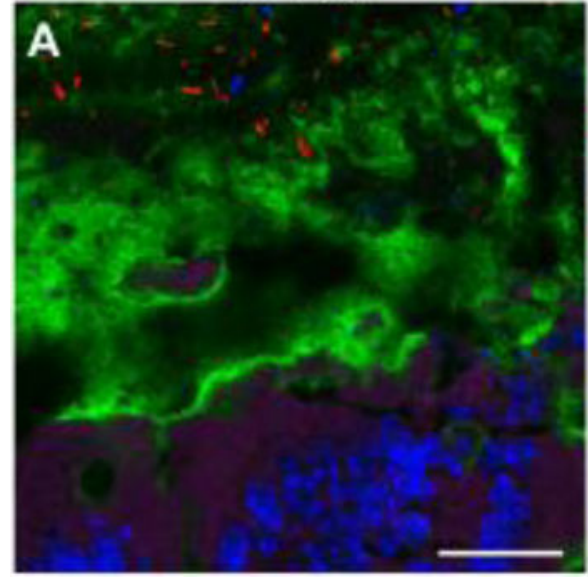

CMC

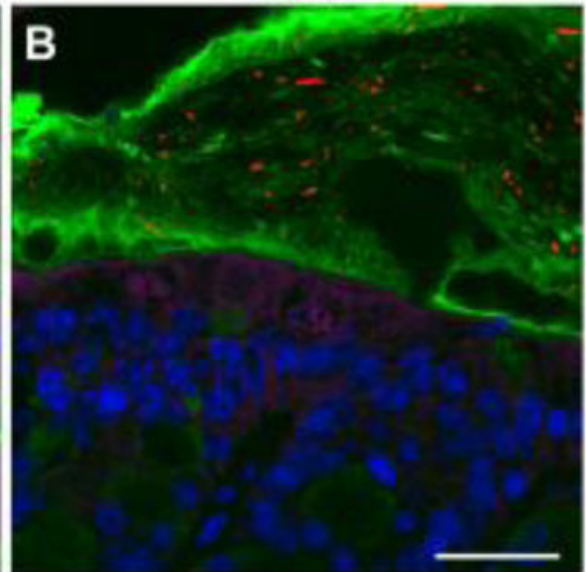

P80

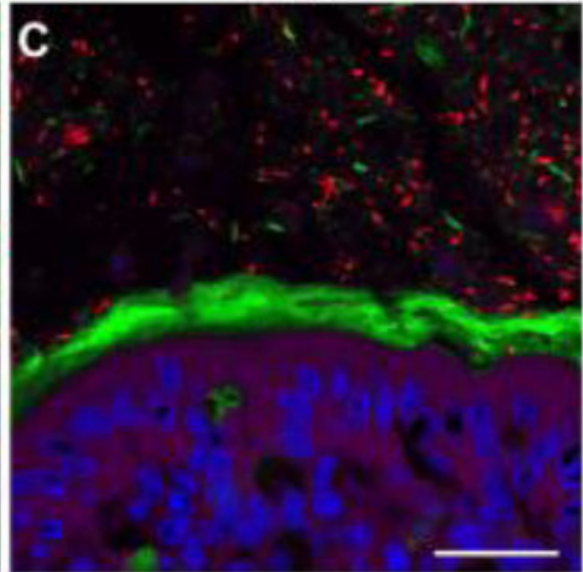

Figure 4.

Exposure of mice to emulsifiers (1\% CMC (B) or 1\% P80 (C)) in drinking water for 12 weeks decreased mucus (Muc2 (green)) thickness and decreased distance between bacteria (red) and colonic epithelium (actin (purple), DNA (blue)). Scale bar $=20 \mu \mathrm{m}$. Adapted from (120). 

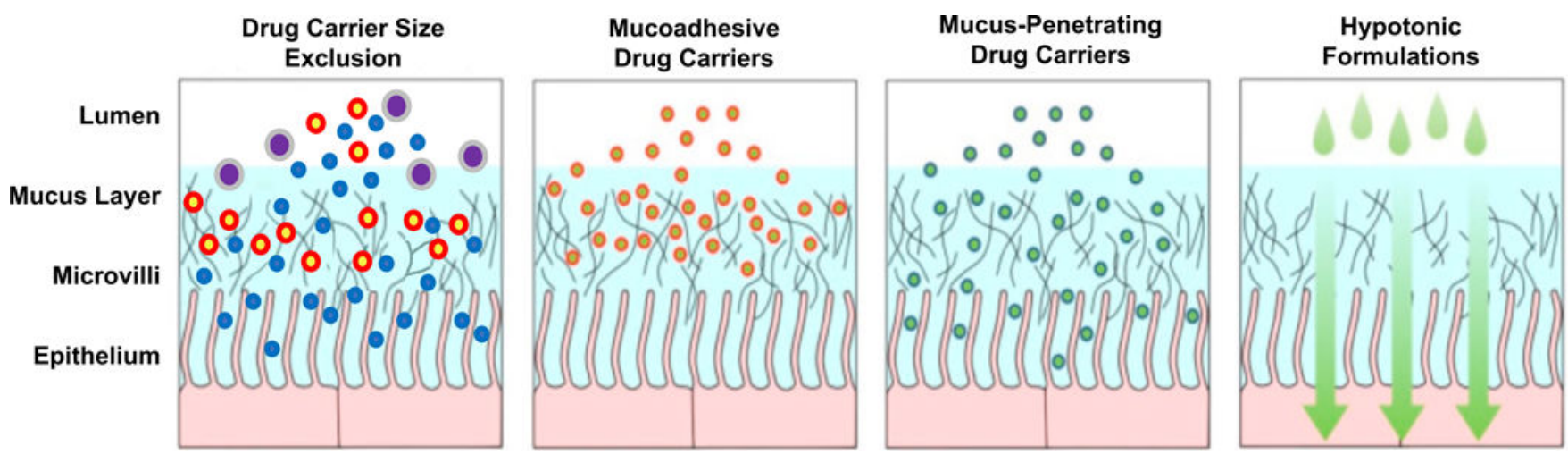

Figure 5.

Drug carrier size, surface properties, and dosing solutions affect the ability to penetrate mucus and reach underlying epithelium. Large drug carriers are size excluded, mucoadhesive drug carriers can adhere to mucus to increase residence time, but may be eliminated due to mucus clearance, and mucus-penetrating drug carriers have minimal interactions to allow penetration of the mucus layer. Dosing formulation properties (i.e. large volume, or hypotonic formulations) improve drug carrier distribution and retention in the mucus layer. Adapted from (150). 